\title{
UNA RECONSTRUCCIÓN DE LA IDEA DE SUTHERLAND DE PATRONES Y PROCESOS DELICTIVOS A PARTIR DEL PRIMER DURKHEIM
}

\begin{abstract}
Alfonso Serrano Maíllo ${ }^{1}$
Resumen: La idea de patrones y procesos delictivos fue propuesta por SUTHERLAND, si bien no definió muy bien estos conceptos ni la relación que existe entre ellos. En esta obra afrontamos este reto partiendo del trabajo de DURKHEIM. De acuerdo con el mismo, una serie de procesos determinan la celebración de y la participación en interacciones o ritos; éstos hacen nacer determinados patrones; finalmente, algunos de éstos gozan de fuerza causal y de este modo influyen en los procesos. Los patrones estructurales se estudian a partir de la concepción durkheimiana de solidaridad mecánica y orgánica que aparece fundamentalmente en el libro La división del trabajo social (1893). Patrones estructurales relevantes para la distribución del delito son la urbanización, la desigualdad o los ciclos económicos, por citar unos pocos ejemplos.

Recibido: abril 2019. Aceptado: octubre 2019

1 Profesor Titular de Derecho penal y Criminología. ORCID ID: 0000-00032545-0908.

Departamento de Derecho penal y Criminología, UNED. Calle Obispo Trejo, 2, 28040 Madrid. Email: aserranom@der.uned.es

El autor desea agradecer las observaciones realizadas por dos revisores anónimos.
\end{abstract}


Los patrones culturales se pueden estudiar a partir de la concepción durkheimiana de cultura en términos simbólicos que aparece en el libro Las formas elementales de la vida religiosa (1912), la obra maestra de este autor. Sin embargo, la misma ha pasado más bien desapercibida en una Criminología que se ha inspirado más por la relativamente sencilla versión de valores y normas de SELLIN. Se puede apreciar este enfoque en el estudio de culturas, subculturas y conflictos culturales. Finalmente, procesos relevantes son los individuales, de crianza y socialización y de grupo. Cada una de estas categorías han dado lugar a importantes hallazgos e incluso explicaciones en Criminología.

Palabras clave: patrones, procesos, criminalidad, ritos/interacciones.

\title{
A RECONSTRUCTION OF SUTHERLAND'S CONCEPT OF CRIMINAL PATTERNS AND PROCESSES WITHIN THE FIRST DURKHEIM'S THEORETICAL MODEL
}

\begin{abstract}
The concept of criminal patterns and processes was originally proposed by SUTHERLAND, though neither him or his followers offered clear definitions or an explanation of what relationship exists between them. In this paper, we focus in these concepts and their relationship relying on the first DURKHEIM'S theoretical model. According to DURKHEIM, certain processes determine the celebration of interactions and rites, as well as who will participate in them. As a consequence of interactions and rites, patterns appear; and then some of these patterns display causal force and, as a consequence, processes appear. Structural patterns can be understood under DURKHEIM'S idea of mechanical and organic solidarity as described in The division of social labour (1893). Structural patterns which are relevant for the distribution of crime are the degree of urbanization, inequality o economic cycles, to mention a few examples. Cultural patterns can be understood under DURKHEIM'S concept of culture in symbolic terms as described in The elementary forms of religious life (1912), DURKHEIM'S masterpiece. Nevertheless, this concept of culture has not been very influential in Criminology, that has been inspired by SELLIN'S simpler version of values and norms. This approach can be found in the study of delinquent subcultures and cultural conflicts. Finally, important processes include individual processes, socialization processes, and group processes. Each of these categories has inspired important findings and even explanations in Criminology.
\end{abstract}

Key words: patterns, processes, criminality, interactions/rites. 


\section{Introducción}

La investigación sobre patrones y procesos delictivos tiene en Criminología un carácter fundamentalmente descriptivo e inductivo ${ }^{2}$. Esto es quizá sorprendente puesto que SUTHERLAND construye su propuesta a partir de la teoría de la asociación diferencial. Al mismo tiempo, estos conceptos de patrones y procesos cumplen una importante función sistemática al ofrecer criterios para la idea de organización del conocimiento que subyace a su famoso manual ${ }^{3}$. Por lo demás, aunque estos conceptos subyacen a muchos trabajos, en general no han tenido una gran influencia en Criminología, ni siquiera entre los estudiosos de SUTHERLAND ${ }^{4}$. En los países de habla hispana, el trabajo más importante encuadrado en el trabajo de este autor norteamericano es el de ALLER sobre delincuencia de cuello blanco, aunque no recurre a esta terminología en sentido estricto, ofrece pinceladas de patrones y procesos ${ }^{5}$. En este trabajo me propongo profundizar en la concepción que SUTHERLAND y más tarde también CRESSEY tuvieron de estos dos conceptos, ofrecer una reconstrucción a partir de sus ideas nucleares y proponer una explicación de las relaciones entre ambos sobre la base de la obra del primer DURKHEIM.

SUTHERLAND definió la Criminología sobre la base de las funciones que desempeña como "el cuerpo de conocimientos sobre el delito como fenómeno social. Incluye dentro de su ámbito los procesos de elaboración de las leyes, de infracción de las

2 Así, BUSHWAY, S., P. COOK y M. PHILLIPS, "The net effect of the business cycle on crime and violence", en Economics and youth violence. Crime, disadvantage, and community (R. ROSENFELD et al. eds.), New York y London: New York University Press, 2013, p. 48.

3 SUTHERLAND, E. H. y D. R. CRESSEY, Criminology, 6. ${ }^{\text {a }}$ ed., New York [etc.]: J.B. Lippincott Company, 1960, p. v.

4 FRIEDRICHS, D. O., I. SCHOULTZ y A. JORDANOSKA, Edwin H. Sutherland, New York: Routledge, 2018, passim.

5 ALLER, G., Criminalidad del poder económico. Ciencia y praxis, Montevideo y Buenos Aires: BdeF, 2011, passim. 


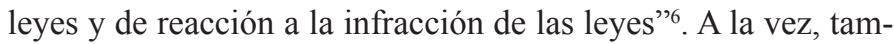
bién se ocupa de la extensión del fenómeno delictivo, envolviendo no sólo el análisis de las tasas de criminalidad y su evolución, sino si el delito se concentra en determinados grupos, lugares, etc. ${ }^{7}$. Este mismo autor, que sigue entre los más citados pese a su desaparición en 1950, es quien introduce la idea de patrones $y$ procesos delictivos ${ }^{8}$. Ya en la primera edición de su conocido manual incluye secciones sobre variables sociodemográficas, estructura social, condiciones físicas y mentales, etc. ${ }^{9}$. Sin embargo, en esta aproximación inaugural de 1924 las trata simplemente en relación con la causación del delito -y no, verbigracia, en sí mismas y como hechos conocidos (con los que debe ser coherente una teoría). En este primer esfuerzo, SUTHERLAND aún no utiliza la terminología de patrones y procesos de modo consistente, aunque sí recurre a estos sustantivos ${ }^{10}$.

El interés específico de SUTHERLAND por la Criminología comienza con su llegada a la Universidad de Illinois en 1919; y el manual de 1924 fue su primera publicación importante sobre la materia, cuando contaba con 41 años de edad ${ }^{11}$. Debido en parte a la buena acogida de este trabajo ${ }^{12}$, fue pasan-

6 SUTHerland, E. H., Principles of Criminology, 2. ${ }^{\mathrm{a}}$ ed., Chicago y Philadelphia: J.B. Lippincott, 1934, p. 3; SUTHERLAND, E. H. y D. R.

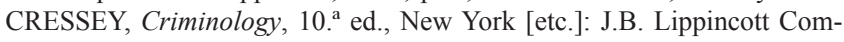
pany, 1978, p. 1.

7 SUTHERLAND, E. H., Criminology, Philadelphia y London: J.B. Lippincott, 1924, p. 11; SUTHERLAND y CRESSEY, Criminology, 10. a ed., cit., p. 29.

8 SUTHERLAND, Criminology, cit., p. 111 sobre todo.

9 SUTHERLAND, Criminology, cit., pp. 89-182.

10 SUTHERLAND, E. H., The Sutherland papers (A. COHEN et al. eds.), Bloomington, IN: Indiana University Press, 1956, p. 112, señala que los conceptos que habitualmente utilizamos en Criminología suelen ser imprecisos.

11 GEIS, G. y C. GOFF, "Introduction”, en E. H. SUTHERLAND, White collar crime. The uncut version, New Haven y London: Yale University Press, 1983, p. xxvi.

12 GAYLORD, M. S. y J. F. GALLIHER, The Criminology of Edwin H. Sutherland, New Brunswick, NJ y London: Transaction, 1988, pp. 12-13 y 75-76. 
do durante los siguientes años por varias universidades e instituciones hasta que llegó a la Universidad de Indiana en 1936. Durante este tiempo pudo profundizar en la materia y madurar su concepción de ésta ${ }^{13}$. Por ello, la segunda edición del manual, diez años después de la primera, es una versión muy mejorada, con ampliaciones y cambios significativos. A partir de ahí -y de modo más nítido en la cuarta edición de $1949^{14}$ - SUTHERLAND es más claro en que algunos de estos patrones y procesos no tienen que tener necesariamente un rol causal sobre el delito, pero que no por ello son menos relevantes ${ }^{15}$. Por ejemplo, el sexo, la variable más sólidamente relacionada con la criminalidad, no es una causa del delito ${ }^{16}$. Ahora bien, pese a todo, la idea que subyace al tratamiento de esos elementos en la segunda edición de 1934 es que la criminalidad se desarrolla a través de una serie de procesos que tienen una naturaleza social y que se encuentran presentes en todos los ámbitos de la sociedad ${ }^{17}$-esto es, con un tono etiológico. SUTHERLAND y sus seguidores, quizá con cierta ambigüedad, tratan de combinar desde este momento ambas ideas: hechos asociados con el delito; y procesos causales de naturaleza social a través de los cuales se desarrolla la criminalidad.

Una aclaración de este segundo punto que aparece ya en 1934 es que ciertos procesos sociales tienen el efecto de exponer a los individuos a contextos diferenciales en los que pueden predominar las definiciones favorables a la infracción de las nor-

13 GAYLORD y GALLIHER, The Criminology..., cit., pp. 83-100; GEIS y GOFF, "Introduction", cit., pp. xxvi-xxviii.

14 SUTHERLAND, E. H., Principles of Criminology, 4. ${ }^{\text {a }}$ ed., Chicago [etc.]: J.B. Lippincott, 1949, p. 3.

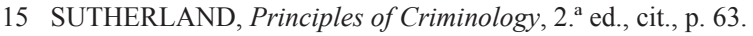

16 SUTHERLAND, Principles of Criminology, 2. ${ }^{\text {a }}$ ed., cit., p. 93; el mismo, Principles of Criminology, 3. ${ }^{\mathrm{a}}$ ed., Chicago y Philadelphia: J.B. Lippincott, p. 101.

17 SUTHERLAND, Principles of Criminology, 2. ${ }^{\text {a }}$ ed., cit., pp. 63 y 181; el mismo, Principles of Criminology, 3. ${ }^{\mathrm{a}}$ ed., pp. 69 y 199; el mismo, Principles of Criminology, 4. ${ }^{\text {a }}$ ed., cit., p. 199. 
mas $^{18}$. Por ejemplo, la familia determina la posición geográfica y social del hogar en la comunidad y ello a su vez determina, por lo tanto, "los tipos de patrones de comportamiento con los que el niño o la niña se van a encontrar" ${ }^{\text {. }}$. Estos contextos diferenciales, que tienen la naturaleza de hechos regulares agregados, es a mi juicio a lo que SUTHERLAND quiere referirse con el concepto de patrón en sentido estricto. El problema es que SUTHERLAND utiliza el término patrón en dos sentidos diferentes, en parte por una economía de palabras y en parte por una cierta ambigüedad.

Veámoslo con un ejemplo. SUTHERLAND escribe que "Los principios del proceso de asociación a través del cual se desarrolla el comportamiento criminal son los mismos que los principios del proceso de asociación a través del cual se desarrolla el comportamiento respetuoso de las normas, pero los contenidos de los patrones presentes en la asociación difieren" ${ }^{20}, \mathrm{o}$ sea que los patrones tienen contenidos -quizá sean definiciones o conjuntos de definiciones- más que ser contextos regulares a los que uno se ve expuesto a causa de ciertos procesos. SUTHERLAND no se refiere aquí a los contenidos presentes en la asociación sino a los contenidos de los patrones presentes en la asociación. Pero una cosa son los patrones como contextos a los que uno se ve expuesto como consecuencia de una serie de procesos -los adultos con un empleo van al trabajo, los niños al colegio-, contextos que son regularidades fácticas con una entidad propia, agregada y autónoma; y otra los patrones como los contenidos o definiciones que puedan existir en dichos contextos. La clave está en entender que las definiciones favorables a la infracción de las normas no se distribuyen aleatoriamente por la sociedad sino que se concentran en contextos regulares que

18 SUTHERLAND, Principles of Criminology, 2. ${ }^{a}$ ed., cit., p. 159; el mismo, Principles of Criminology, 3. ${ }^{\mathrm{a}}$ ed., cit., pp. 166 y 175; el mismo, Principles of Criminology, 4. ${ }^{\mathrm{a}}$ ed., cit., p. 164.

19 SUTHERLAND, E. H., D. R. CRESSEY y D. F. LUCKENBILL, Principles of Criminology, 11. a ed., New York: General Hall, 1992, p. 212.

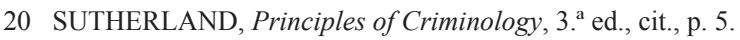


no sólo demandan una explicación, sino que su propia existencia no es evidente ni aproblemática: es menester estudiar de dónde surgen y qué efectos tienen esas regularidades agregadas que aquí llamaremos patrones -dentro de los cuales puede existir un exceso de definiciones favorables a la infracción de las normas, definiciones favorables al respeto de las normas o bien existir un equilibrio o bien neutralidad. SUTHERLAND parece utilizar el término patrón en dos sentidos distintos, uno estricto y técnico; y otro amplio y no técnico. Cuando SUTHERLAND añade en otros lugares -tímidamente ya en la primera edición del manualcon un matiz individual y subjetivo que ciertos patrones pueden adoptarse o asimilarse por los sujetos ${ }^{21} \mathrm{o}$ que una persona puede desarrollar ciertos patrones de comportamiento ${ }^{22}$, está utilizando patrón en el sentido no técnico. Cuando SUTHERLAND habla del tamaño de la comunidad o la clase social como patrones, está utilizando patrón en el sentido técnico ${ }^{23}$-entre otros motivos, dichos elementos no pueden tener ningún contenido, aunque sí albergar definiciones de modo diferencial. Ambos esquemas pueden describirse del modo que sigue:

Sentido técnico de patrón en SUTHERLAND:

$$
\text { proceso } \rightarrow \text { patrón } \leftrightarrow \text { definiciones }
$$

Sentido no técnico de patrón en SUTHERLAND:

$$
\text { proceso } \rightarrow \text { patrón/definiciones }
$$

La terminología de los patrones en un sentido significativo $^{24}$-la de procesos es anterior- aparece por primera vez con nitidez en la tercera edición del manual de SUTHERLAND; se

21 SUTHERLAND, Criminology, cit., p. 121; vid., más nítidamente, el mismo, Principles of Criminology, 3. ${ }^{\mathrm{a}}$ ed., cit., p. 4.

22 SUTHERLAND, The Sutherland papers, cit., p. 113.

23 SUTHERLAND et al., Principles of Criminology, 11. ${ }^{\text {a }}$ ed., cit., p. 173.

24 SUTHERLAND utiliza el término patrón en otros sentidos. Así, en la primera edición de su manual patrón se refiere a patrones de comportamiento generales de un individuo que surgen de interacciones que tienen lugar después del nacimiento, Criminology, cit., pp. 120-121 y 124. Por supuesto, en otros lugares la palabra patrón aparece con un sentido no técnico, 627. 
hace más frecuente a partir de la quinta edición, actualizada por CRESSEY en 1955; y finalmente, aunque el término patrón es habitual en las siguientes ediciones, hasta la décima, de 1979, no es empleada en los títulos y epígrafes de los capítulos. La idea general aquí predominante es que una serie de procesos tienen la consecuencia de exponer a los individuos a patrones (en sentido estricto) en los que predominan definiciones pro- o anticriminales. No importa repetir que estos patrones no son otra cosa que contextos en los que predomina la exposición a definiciones desfavorables al respeto de la ley, aunque también existen contextos neutrales y, no hace falta decirlo, contextos en que predomina la exposición a definiciones favorables al respeto de la ley. Evidentemente, nuestros autores evocan en este planteamiento el mecanismo de la asociación diferencial.

Pasemos a desarrollar algo más la idea de patrones y procesos delictivos en estos autores, buscando el mecanismo que subyace a los mismos y dejando ya de lado la evolución de este pensamiento a lo largo de más de cincuenta años. SUTHERLAND y CRESSEY sostienen la existencia de unos hechos bien conocidos sobre el delito que una teoría debe ser capaz de explicar completamente -si bien ninguna propuesta teórica estaría en condiciones de ofrecer una tal explicación de modo exhaustivo ${ }^{25}$. Denominan a los mismos "hechos definitorios"26. Estos hechos se pueden dividir en dos grupos: variaciones en las tasas de criminalidad en razón "de la edad, el sexo, la raza, el estatus socioeconómico, la educación y otras variables" por un lado; e "incidencia entre criminales y delincuentes de varias características y procesos físicos, psicológicos y sociales" ${ }^{27}$. Como veremos, nuestra reconstrucción denominará a estas dos constelaciones de fenómenos, respectivamente, patrones y pro-

25 SUTHERLAND y CRESSEY, Criminology, 10. ${ }^{\text {a }}$ ed., cit., pp. 153-154; SUTHERLAND et al., Principles of Criminology, 11. ${ }^{\mathrm{a}}$ ed., cit., pp. vii y 172.

26 SUTHERLAND y CRESSEY, Criminology, $10{ }^{a}$ ed., cit., p. 154; SUTHERLAND et al., Principles of Criminology, 11. ${ }^{\text {a }}$ ed., cit., p. 171.

27 SUTHERLAND et al., Principles of Criminology, 11. ${ }^{\text {a }}$ ed., cit., p. vii. 
cesos delictivos (términos que nuestros protagonistas también utilizan) -y tratará de aclarar qué conexión existe entre ellos. En el planteamiento original de SUTHERLAND -como en el nuestro- los primeros tienen una naturaleza macro o agregada; y, los segundos, individual o quizá meso. Como se ha advertido más arriba, puede hipotetizarse que estos fenómenos desempeñan un rol causal sobre el delito ${ }^{28}$ o no $^{29}$.

SUTHERLAND y sus colegas no hablan de las condiciones físicas y mentales individuales -los primeros hechos definitorios que apuntan ${ }^{30}$ - con los términos patrones o procesos delictivos, aunque son hechos -micro. A su juicio está claro que las mismas no desempeñan ningún rol causal sobre el delito, excepto "si afectan o están afectadas por interacción social"31. Esto apunta a que el planteamiento de SUTHERLAND y sus socios está determinado por su teoría de la asociación diferencial, de modo que los patrones y procesos siguen siendo preferiblemente fenómenos criminológicos causalmente relevantes desde el punto de vista de esta explicación.

El segundo grupo de hechos definitorios que mencionan SUTHERLAND y sus seguidores son las tasas de criminalidad, entendidas como "tasas de delito para ciertas categorías de individuos", como los jóvenes -o la edad, si se prefiere el lenguaje de las variables-, los hombres -sexo- o los individuos de color -raza-, entendidos estos tres factores como "estatutos sociales en vez de características físicas"; tamaño de la comunidad y cla-

28 SUTHERLAND y CRESSEY, Criminology, $10 .^{a}$ ed., cit., p. 137; SUTHERLAND et al., Principles of Criminology, 11. ${ }^{\mathrm{a}}$ ed., cit., p. 151.

29 SUTHERLAND y CRESSEY, Criminology, $10 .^{\text {a }}$ ed., cit., p. 136; SUTHERLAND et al., Principles of Criminology, $11 .^{\text {a }}$ ed., cit., p. 150.

30 SUTHERLAND et al., Principles of Criminology, 11. ${ }^{\text {a }}$ ed., cit., p. 172.

31 SUTHERLAND y CRESSEY, Criminology, $10 .^{a}$ ed., cit., p. 136; SUTHERLAND et al., Principles of Criminology, 11 . $^{\mathrm{a}}$ ed., cit., pp. 119 y 150 , de donde se toma la cita. Si estas condiciones pueden desplegar un efecto indirecto sobre el delito en cuanto que pueden afectar a las interacciones sociales -lo cual parece ciertamente plausible, como que quienes abusan del alcohol frecuenten los mismos lugares y se relacionen entre sí, 143-145-, entonces ciertamente pueden desplegar un rol causal (mediato) sobre el delito. 
se social ${ }^{32}$. Nuestros investigadores hablan aquí de "patrones"33. Ahora bien, si el énfasis se pone estrictamente en las tasas criminalidad de estos grupos, no existiría ninguna diferencia con las condiciones físicas y mentales. Por un lado, se trataría de un plano descriptivo y lo mismo que los jóvenes -ya sea en sentido biológico o social- delinquen más que los adultos, podría ser que quienes abusan del alcohol también infringieran normas legales de modo desproporcionado; y, por otro lado, si SUTHERLAND y sus socios descartan que las condiciones físicas y mentales sean una causa inmediata del delito, la edad, el sexo o la raza sencillamente no pueden serlo ${ }^{34}$. De hecho, nuestros autores parecen abandonar aquí su preocupación causal y conceden que se refieren a "condiciones sociales con las que varían las tasas delictivas" ${ }^{\prime 35}$-así como a proponer, de modo consistente, explicaciones para tales ratios diferenciales en razón de la edad, el sexo, etc. en línea con la teoría de la asociación diferencial ${ }^{36}$. Existe una cierta ambivalencia en el rol causal de estos factores en estos autores, lo cual podría entenderse como que son a la vez causa y efecto de otros fenómenos. Un ejemplo es que cuando hablan de patrones familiares no sólo se refieren a la concentración del delito en familias con ciertas características, lo que encaja más propiamente con el concepto de patrón -miembros delincuentes, padres ausentes...-, sino que también hacen hincapié en el rol causal de estas características respecto a los hijos e hijas de las familias ${ }^{37}$ : si en el primer caso se refiere a algo que

32 SUTHERLAND et al., Principles of Criminology, 11. ${ }^{\text {a }}$ ed., cit., p. 151.

33 SUTHERLAND et al., Principles of Criminology, 11. ${ }^{\text {a }}$ ed., cit., p. 173, por ejemplo.

34 Aunque sí podrían serlo variables que afectan o son afectadas por la edad, como las fuentes de frustración o el autocontrol.

35 SUTHERLAND et al., Principles of Criminology, 11. ${ }^{\text {a }}$ ed., cit., p. 171.

36 SUTHERLAND et al., Principles of Criminology, 11. a ed., cit., pp. 158-159, 162-164, 170-171, 180-181 y 183-185.

37 SUTHERLAND y CRESSEY, Criminology, $10 .^{a}$ ed., cit., p. 212; SUTHERLAND et al., Principles of Criminology, 11. a ed., cit., pp. 202-203, los autores señalan que la escuela tiene unos efectos semejantes a los de la familia, 232-237. 
demanda una explicación y tiene un carácter dependiente; en el segundo explica la desviación y tiene un carácter por lo tanto independiente o predictivo.

Cuando SUTHERLAND y sus seguidores terminan con la edad, el sexo, la raza y la clase social, pero sobre todo la región, la ciudad, el barrio... -a los que expresamente denominan, a estos últimos, patrones culturales-y se adentran en los patrones familiares se hace más claro que ya no hablan de tasas de criminalidad, sino de condiciones con un rol causal sobre el delito a nivel micro: que unos miembros de la familia tengan tendencias criminales, al abuso del alcohol o a la inmoralidad, que uno o los dos padres estén ausentes por fallecimiento, divorcio o abandono, etc. podrían desplegar una influencia causal sobre la criminalidad de otros de sus miembros ${ }^{38}$. Por ejemplo, afirman en este tono microcausal que "la relación entre el hogar roto y la delincuencia es relativamente débil" ${ }^{39}$. Hasta ese momento, la idea de patrón que ha predominado ha sido otra: un fenómeno agregado relativo a la concentración desproporcionada de delitos en ciertos grupos sociales y quizá también áreas físicas, con una orientación descriptiva que demandaba una explicación.

Sin solución de continuidad pasan SUTHERLAND y los continuadores de su trabajo a "procesos generales", presumiblemente familiares, y escriben que "De los análisis precedentes de las condiciones del hogar en relación con la delincuencia, se derivan (appear) cinco procesos principales" ${ }^{40}$. Estos procesos exponen al individuo a patrones en los que predominan definiciones prodelictivas. En el primer proceso, la familia expone de modo directo al niño a patrones de comportamiento favorables a la criminalidad; en el segundo proceso, la familia determina la posición geográfica y social del hogar en la comunidad y, por lo tanto, "los tipos de patrones de comportamiento con los que el niño o la niña se van a encontrar"; en el tercer proceso, con

38 SUTHERLAND et al., Principles of Criminology, 11. a ed., cit., pp. 202-203.

39 SUTHERLAND et al., Principles of Criminology, 11. ${ }^{\text {a }}$ ed., cit., p. 206.

40 SUTHERLAND et al., Principles of Criminology, 11. ${ }^{\text {a }}$ ed., cit., p. 211. 
un cariz más cualitativo, el hogar determina no ya con quiénes se van a relacionar, sino los "valores de prestigio" de esos individuos y grupos; el cuarto proceso implica que el infante que no está a gusto en su casa es más probable que se vea expuesto más a patrones de comportamientos criminales y menos a patrones de comportamientos anticriminales; finalmente, en el quinto proceso los padres sencillamente no presentan a la prole patrones de comportamientos anticriminales porque están ausentes, son apáticos o por lo que sea ${ }^{41}$. Teniendo en cuenta que este pasaje debe entenderse en sentido técnico (procesos $\rightarrow$ patrones $\leftrightarrow$ definiciones), la familia puede ser un contexto en el que sujeto se ve expuesto a definiciones diferenciales - procesos primero y quinto-; o bien los procesos familiares determinan que el infante se vea expuesto a contextos en los que predominan definiciones diferenciales - procesos segundo, tercero y cuarto. Todos estos patrones son contextos -la familia, el barrio, la calle- que implican asociación diferencial con sujetos desviados y, por lo tanto, en el caso habitual a un exceso de definiciones favorables a la infracción de las normas.

Como se señalaba más arriba, las familias también son instituciones sociales básicas que generan patrones delictivos o respetuosos de las normas. Estas instituciones básicas -la mencionada familia, las económicas, las gubernamentales, las educativas, las religiosas y los medios- tienen el efecto, de nuevo, determinan que el individuo se vea expuesto a patrones en los que predominan definiciones pro- o anticriminales. Verbigracia, desde el punto de vista de las instituciones económicas, la pobreza urbana determina que quienes la sufren se vean abocados a contextos en los que predomina el contacto con definiciones procriminales y se vean aislados de contextos dominados por definiciones conductuales anticriminales ${ }^{42}$. Es fácil ver aquí de nuevo los pilares de la teoría de la asociación diferencial.

41 SUTHERLAND et al., Principles of Criminology, 11. ${ }^{\text {a }}$ ed., cit., p. 211-213. Mencionan otros dos procesos, aunque no les conceden mayor importancia, 213.

42 SUTHERLAND et al., Principles of Criminology, 11. a ed., cit., p. 224. 
Como vemos, a pesar de su seminal contribución, ni SUTHERLAND ni sus seguidores ofrecen una definición o aclaración explícita de su planteamiento, cuando no encierra el mismo algo de ambigüedad ${ }^{43}$. Ello es debido a que el mismo se enmarca en su teoría de la asociación diferencial, que le antecede desde un punto de vista lógico -en vez de partir de un modelo más general en el que integrar su propuesta explicativa, una estrategia a mi juicio más prometedora. Por este motivo, aquí tendremos que reconstruir estos conceptos para darles un contenido autónomo y más general partiendo de la obra de DURKHEIM. A mi juicio, es difícil que una teoría criminológica pueda ofrecer un planteamiento tan general como el que intenta dar SUTHERLAND a la suya; antes al contrario, una explicación debe construirse sobre la base de teoría sociológica más amplia y general que la precede lógicamente. Nuestro planteamiento es el reflejado en el Gráfico número 1.

\section{Gráfico 1. Relación entre patrones y procesos}

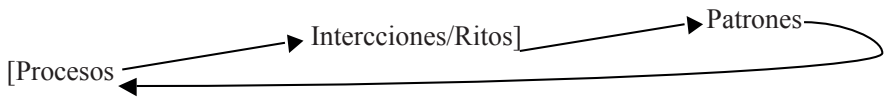

Debe advertirse de entrada que, como se ha dicho, muchos -quizá la mayoría- de los factores que mencionaremos no guardan una relación causal directa $-\mathrm{y}$ a menudo ni siquiera indirecta- con el delito. Del mismo modo, esos tres elementos -patrones, interacciones/ritos y procesos- pueden desagregarse en otros, si bien tanto por sencillez como por fidelidad al planteamiento originario de DURKHEIM conservaremos este esquema. Sí se desagrega del par procesos-patrones el elemento interacciones/ritos, que tiene un carácter ontológicamente autónomo ${ }^{44}$, aunque por parsimonia lo trataremos junto a los proce-

43 GAYLORD y GALLIHER, The Criminology..., cit., p. 133.

44 GOFFMAN, E., Interaction ritual. Essays on face-to-face behaviour, New York: Anchor Books, 1967, pp. 84-85, 94, 105, 113-114 y 134-136. 
sos -de ahí los corchetes. Puede adelantarse lo siguiente: una serie de procesos determinan la celebración de y la participación en interacciones o ritos; los mismos a su vez hacen nacer de modo emergente determinados patrones; finalmente, algunos de estos patrones gozan de fuerza causal y de este modo influyen en los procesos de la parte izquierda del esquema. Habrá que volver sobre este esquema debido a su carácter problemático ${ }^{45}$.

La idea de patrón evoca la distribución u organización de un fenómeno, por ejemplo de la criminalidad o de variables relacionadas con la misma; los patrones son agrupaciones de cosas semejantes, de eventos con una estructura parecida. En sentido más técnico, el patrón se crea $-\mathrm{y}$ recrea continuamente ${ }^{46}$ - a partir de interacciones entre individuos y grupos, es un elemento emergente de estas relaciones. La idea de patrón tiene un carácter supraindividual, se ubica en un nivel de análisis agregado ${ }^{47}$. Los patrones responden a un carácter más o menos fijo y resistente al cambio como pueden ser la estructura jurídico-penal, el grado de industrialización de un país o sus infraestructuras, pero también pueden ser más efímeros y cambiantes como los ciclos económicos. Ejemplos de patrones son las tasas de delincuencia y su distribución a lo largo de diversos países y regiones; el grado de urbanización; o la distribución de la riqueza. Aunque nuestro interés en estos procesos en esta obra se limita en lo

45 Una crítica y propuesta alternativa, en particular opuesta a la idea de emergencia en el marco de lo que denomina el comportamiento subinstitucional, HOMANS, G. C., Social behavior. Its elementary forms, 2. ${ }^{\mathrm{a}}$ ed., New York: Harcourt, Brace, Jovanovich, 1974, pp. 356-371.

46 TURNER, J.H., "A behavioral theory of social structure", Journal for the Theory of Social Behavior, 18, 4, 1988, p. 362.

47 SERRANO MAÍlLO, A., Introducción a la Criminología, 6. ${ }^{\mathrm{a}}$ ed., Madrid: Dykinson, 2009, pp. 206-211. En el estricto ámbito criminológico no existen teorías multinivel plausibles, pese a que se reclama su oportunidad, ROSENFELD, R., C. S. FLORENCE, X. FANG y M. EDBERG, "Introduction", en Economics and youth violence. Crime, disadvantage, and community ( $\mathrm{R}$. ROSENFELD et al. eds.), New York y London: New York University Press, 2013, pp. 13-14. Sobre si son posibles, escéptico, SERRANO MAÍLLO, Introducción..., cit., p. 211. Volveremos sobre esta cuestión más adelante. 
sustancial a su influencia causal en los procesos responsables de la criminalidad a nivel individual y en su correlativa conexión con las tasas de delincuencia, en realidad es igualmente relevante su aparición de modo emergente a partir de procesos y ritos/interacciones ${ }^{48}$. En efecto, el delito se concentra de modo desproporcionado en ciertos países o regiones; en las ciudades; $\mathrm{y}$, algunas de sus modalidades, en momentos de auge económico. Factores como los recién mencionados tienen una naturaleza predominantemente estructural puesto que se refieren a cómo una sociedad está construida; solo que la estructura es ontológicamente inseparable de la cultura entendida habitualmente en Criminología como valores, creencias, normas, comportamientos y estilos de vida de una sociedad que se transmiten de una generación a otra. En efecto, estructura y cultura son elementos que pueden separarse de modo analítico, pero al mismo tiempo íntimamente relacionados entre sí.

La idea de emergencia, recién reseñada, es nuclear aquí. DURKHEIM la describe como sigue: "Siempre que al combinarse distintos elementos originan, por su misma combinación, fenómenos nuevos, hay que reconocer que estos fenómenos dimanan no de los elementos, sino del todo formado por su unión", si "esta síntesis "sui generis", que constituye toda sociedad, produce fenómenos nuevos, diferentes de los que se engendran en las conciencias individuales, hay que admitir que estos hechos específicos residen en la misma sociedad que los produce y no en sus partes", "No se los puede reabsorber en los elementos sin contradecirse, pues, por definición, suponen algo diferente de lo que contienen dichos elementos" $"$; "La asociación es también, un factor activo que produce efectos especiales. Resulta por sí misma algo nuevo [...] que aparezcan fenómenos cuyas propie-

48 MAYHEW, B. H., "Structuralism versus individualism: Part 1, Shadowboxing in the dark", Social Forces, 59, 2, 1980, p. 339; TURNER, "A behavioral theory...", cit., pp. 365-369.

49 DURKHEIM, E., Las reglas del método sociológico (trad. A. Ferrer), Los Berrocales del Jarama, Madrid: Akal, 1895/1991, pp. 24-25. 
dades características no se encuentran en los elementos de que se componen" ${ }^{, 50}$.

Ciertamente, algunos de los factores que estudiamos bajo estas categorías son relevantes como procesos $y$ como patrones y existe, por lo tanto, un solapamiento ${ }^{51}$. Por ejemplo, el género es por un lado relevante porque afecta a la participación en ritos de los individuos -también a la criminalidad-y es por otro lado relevante como patrón derivado de los mismos -en determinadas posiciones puede haber una ratio de hombres/mujeres variable, o una división del trabajo diferencial. Ambas dimensiones de género se relacionan entre sí.

Por proceso entendemos un fenómeno dinámico que tiene varias fases y está referido de modo más directo a la biografía de las personas y grupos de los que forman parte. La idea de proceso tiene un carácter individual o grupal y se ubica en un nivel de análisis distinto al agregado o macro -dos niveles de análisis ontológicamente diferentes. Ejemplos de procesos que influyen en la participación en ritos/interacciones son el género, la edad, el estatus inmigrante y la desventaja social... que corresponden a un individuo concreto. Todos estos elementos influyen en las interacciones en que uno participa y que crean de modo emergente patrones particulares; solo que estos patrones, una vez generados, también influyen en los individuos $\mathrm{y}$ en sus relaciones ${ }^{52}$. Muchos de estos factores pueden verse como variables, por ejemplo sociodemográficas, de modo que el término proceso debe entenderse de modo flexible, también en cuanto que conectado con los ritos/interacciones. Sin em-

50 DURKHEIM, E., El suicidio. Estudio de Sociología (trad. M. Ruiz-Funes), Madrid: Reus, 1897/1928, p. 340.

51 BUSHWAY, S. y P. REUTER, "Labor markets and crime", en Crime. Public policies for crime control (J. Q. WILSON y J. PETERSILIA eds.), Oakland, Ca.: ICS., 2002, p. 191.

52 Desde un punto de vista analítico, en puridad, los procesos son previos a las relaciones o interacciones $\mathrm{y}$, por lo tanto, también a los patrones, que a su vez influyen sobre los primeros; al mismo tiempo que DURKHEIM concede la primacía a los ritos. 
bargo, al mismo tiempo podemos referirnos a muchas de estas variables como procesos en el sentido de que no son eventos fijos sino que habitualmente gozan de un estatus dinámico. Por ejemplo, el mismo género -que parecería reducirse a una dicotomía - no es algo fijo, determinado... sino algo complejo que se construye; y una construcción a la que podemos contribuir nosotros mismos ${ }^{53}$. CONNELL añade que el género debe verse más bien como un elemento relacional, o sea un marco en el que los individuos actúan ${ }^{54}$. En este sentido, parece asumible incluso en este caso extremo hablar de procesos.

Este esquema durkheimiano que aquí seguiremos es problemático. A su tenor:

1. Una serie de variables y/o procesos determinan la participación en ritos e interacciones.

2. Estos procesos y, más mediatamente, estos ritos e interacciones hacen nacer de modo emergente patrones agregados. Puede verse aquí una conexión micro-a-macro o una causalidad hacia arriba.

3. Los patrones agregados, que gozan de independencia ontológica, ejercen su influencia causal sobre los procesos individuales, esto es tienen también fuerza causal. Puede verse aquí una conexión macro-a-micro o una causalidad hacia abajo.

Sin embargo, este esquema contiene una serie de ambigüedades ${ }^{55}$ e incluso problemas serios cuya solución no es sencilla $^{56}$. A pesar de ello, es un planteamiento a mi juicio plausible y superior a la mayoría de sus alternativas. El problema básico,

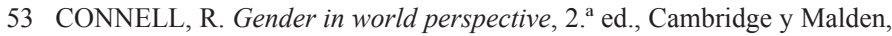
Mass.: Polity, 2009, pp. 5-6.

54 CONNELL, Gender ..., cit., p. 10.

55 TURNER, J.H., -Émile Durkheim's theory of social organization-, Social Forces, 68, 4, 1990, pp. 1090-1092.

56 Vid. más en general LUKES, S., Emile Durkheim. His life and work. A historical and critical study, London: The Penguin Press, 1973, pp. 223 y 228; PARSONS, T., The structure of social action, I. Marshall, Pareto, Durkheim, 2. ${ }^{\text {a }}$ ed., New York: The Free Press, 1968, pp. 361-362. 
desarrollado por GIDDENS, es que la teoría parece asumir que individuos aislados se unen de modo espontáneo y hacen nacer de la nada una entidad nueva y distinta de ellos, que a la vez tiene poderes causales ${ }^{57}$. Si por un lado esto evoca la vieja crítica que DURKHEIM había hecho en su día al concepto de hombre presocial de SPENCER - esto es, un sujeto al margen de la sociedad que a continuación entra en ella ${ }^{58}$, por otro califica de implausible la existencia de unos patrones que existen de modo independiente de los individuos que le dan vida y sobre los que influyen causalmente. Adviértase que la distinción tiene que ser ontológica o no podría hipotetizarse una causalidad hacia abajo -por eso algunas defensas más o menos sofisticadas de este esquema durkheimiano sencillamente rodean el problema más que enfrentarse frontalmente y resolverlo.

\section{Patrones estructurales: un enfoque durkheimiano}

En esta obra distinguimos entre patrones estructurales y culturales. Una cuestión compleja es la relación entre estructura social y cultura ${ }^{59}$. Para afrontarla nos basaremos, como se ha adelantado parcialmente, en la obra conjunta de DURKHEIM ${ }^{60}$.

57 GIDDENS, A., Capitalism and modern social theory. An analysis of the writings of Marx, Durkheim and Max Weber, Cambridge [etc.]: Cambridge University Press, 1971, pp. 87-88; el mismo, The constitution of society. Outline of the theory of structuration, Berkeley, Ca.: University of California Press, 1984, p. 171.

58 GONZÁLEZ SÁNCHEZ, I., -La sacralización del individuo utilitarista", en Anomia, cohesión social y moralidad. Cien años de tradición durkheimiana en Criminología (I. GONZÁLEZ SÁNCHEZ y A. SERRANO MAÍLLO eds.), Madrid: Dykinson, 2018, pp. 115-143.

59 Existen muchas concepciones de la conexión entre estructura y cultura, así como enfoques que reducen una a la otra. Por ejemplo, en SUTHERLAND (1) se produce una cierta conflación de estructura y cultura en cuanto que la primera se entiende en términos de normas compartidas, en línea con ciertas corrientes del interaccionismo simbólico.

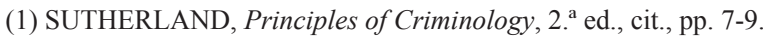

60 Aunque existen periodos en el trabajo de DURKHEIM - siendo el más relevante el tardío-, también existe una relación entre ellos, SERRANO MAÍ- 
La estructura social hace referencia a relaciones sociales ordenadas y duraderas; y la cultura a símbolos compartidos. Se trata de elementos emergentes de ritos/interacciones. Bajo condiciones normales, estos dos elementos aseguran el orden y la solidaridad social y, por lo tanto, el mantenimiento de los sistemas sociales y su cambio pacífico ${ }^{61}$. Aunque estructura y cultura pueden estudiarse como elementos distintos y con una existencia autónoma y específica, esta afirmación debe matizarse mucho ya que su conexión es tan íntima que no pueden entenderse por separado, sino integrados en un único sistema. Estructura y cultura en el fondo son elementos analítica- ${ }^{62}$, y no ontológicamente diferentes ${ }^{63}$.

¿Qué es la estructura social según DURKHEIM? La observación cotidiana revela personas o grupos de personas interaccionando unos con otros, durante un cierto tiempo y con una determinada distancia física y social - por ejemplo, jerárquica ${ }^{64}$.

LLO, A., Firmeza frente al delito y comunidad en la modernidad reflexiva. La tesis extendida de los sentimientos de inseguridad como teoría del control social, Madrid: Dykinson, 2016, pp. 254-255.

61 En efecto, el modelo durkheimiano es dinámico. De este modo, también afectan a la estructura social cambios que se pueden producir a lo largo del tiempo tales como ciclos económicos.

62 KORNHAUSER, R. R., Social sources of delinquency. An appraisal of analytic models, Chicago y London: University of Chicago Press, 1978, pp. 1213; RADCLIFFE-BROWN, A. R., A natural science of society, New York: Free Press, 1957, p. 106.

63 DURKHEIM, E., La división del trabajo social (trad. C. G. Posada), Los Berrocales del Jarama, Madrid: Akal, 1893/1995, pp. 151 y 221. Esta es la forma más habitual de ver la naturaleza de estos elementos en nuestra disciplina, con el añadido también habitual de que la estructura opera sobre la cultura, STEWART, E. A. y R. L. SIMONS, "Race, code of the street, and violent delinquency: A multilevel investigation of neighbourhood street culture and individual norms of violence", Criminology, 48, 2, 2010, pp. 573 y 576; STEWART, E. A., C. J. SCHRECK y R. K. BRUNSON, "Lessons of the street code. Policy implications for reducing violent victimization among disadvantaged citizens", Journal of Contemporary Criminal Justice, 24, 2, 2008, pp. 139-140.

64 COLlins, R., Four sociological traditions, New York y Oxford: Oxford University Press, 1994, p. 187. En muchos debates sobre las cuestiones 
Sin embargo, ello no es aleatorio, sino que se ajusta a unos patrones regulares. Estas relaciones ordenadas, regulares y duraderas conforman la estructura social y reflejan las propiedades organizativas de una sociedad. Dicho de otro modo, la estructura social es lo que subyace a esas relaciones que se observan y que pueden parecer azarosas; son su base interna, su estrato profundo. Adviértase que la estructura es un elemento emergente en el sentido de que (analíticamente) resulta de las interacciones y sus características. Por este motivo se trata de algo esencialmente dinámico, en recreación constante, aunque al mismo tiempo real y tangible. Por supuesto, la estructura es algo distinto a la mera suma de los individuos y sus interacciones regulares. Pero, al mismo tiempo e inmediatamente, la estructura se impone a los individuos, que pueden hacer muy poco para modificar algo objetivo y externo a ellos mismos ${ }^{65}$. No sólo eso: es coercitiva, puede imponer sanciones, constriñe su comportamiento... En una metáfora ilustrativa, JENKS habla de "muros invisibles de prisiones" ${ }^{\prime 6}$. En términos analíticos, los individuos influyen sobre una estructura que no es otra cosa que el producto de sus relaciones e interacciones, de sus ritos; y viceversa: la solidaridad genera interacciones ${ }^{67}$ y las interacciones generan solidaridad ${ }^{68}$.

Quizá es ingenuo juzgar la estructura en términos valorativos, pero, en sí misma considerada, seguro que no es algo malo. DURKHEIM, sin embargo, da un paso más y la valora como algo positivo en el sentido de que permite el orden y la vida colectiva ${ }^{69}$. En efecto, en nuestro autor existe un trasfon-

que revisamos en este artículo suele plantearse la cuestión de qué fue primero. No es que esto sea especialmente importante, pero en el caso de DURKHEIM lo primero y preponderante es el ritual -una forma de comportamiento.

65 DURKHEIM, La división ..., cit., pp. 102-103; el mismo, Las reglas..., cit., pp. 23-24, 29-30 y $42-43$.

66 JENKS, C., Subculture. The fragmentation of the social, London [etc.]: Sage, 2005, pp. 30-32, cita tomada de p. 32.

67 DURKHEIM, La división..., cit., p. 75.

68 DURKHEIM, La división ..., cit., p. 128.

69 DURKHEIM, La división ..., cit., pp. 206 y 215. 
do funcionalista -que entiende que ningún elemento social es caprichoso, sino que cumple una función esencial ${ }^{70}-$, la crítica feroz de lo cual se ha convertido en un lugar común, pero que si se toma como una metáfora más bien libre puede ser útil. La estructura, que es como el "tejido" de lo social"1 , permite la vida social al generar solidaridad de acuerdo con dos tipos: la solidaridad mecánica y la solidaridad orgánica -la famosa dicotomía durkheimiana.

La solidaridad mecánica ${ }^{72}$ corresponde a sociedades poco desarrolladas y se basa en la uniformidad: estructuralmente existe una baja división de lo que DURKHEIM llama el trabajo social. Al mismo tiempo, existe una conciencia colectiva ampliamente compartida y apenas hay disenso; a la par que los símbolos son concretos y nítidos para todo el mundo, como un león en cuanto que animal fuerte y feroz - que signifique lo mismo para todo el mundo. Como en una máquina inanimada, todas las piezas funcionan al unísono ${ }^{73}$.

Sin embargo, cuando las poblaciones aumentan y, por lo tanto, también lo hacen las interacciones, aumenta también la diversidad o diferenciación, o sea la división del trabajo social ${ }^{74}$ -con el acento en el aspecto ocupacional de la diversidad o especialización ${ }^{75}$. Como consecuencia, la conciencia colectiva -0 quizá más propiamente las representaciones colectivas- se hace más ligera y toma más peso la individual; y los símbolos son menos claros y exigen una cierta reflexión por parte del individuo ${ }^{76}$.

70 DURKHEIM, La división ..., cit., pp. 43, 49, 57, 63, 126-127, 151, 216, 327 y 339 .

71 JENKS, Subculture ..., cit., p. 31.

72 DURKHEIM, La división ..., cit., pp. 83-129, 151-154 y 267-270.

73 LUKES no cree que la analogía máquina-organismo vivo deba tomarse demasiado en serio, Emile Durkheim ..., cit., p. 148.

74 DURKHEIM, La división ..., cit., pp. 146 y 232.

75 TURNER, J.H., "Émile Durkheim's theory of integration in differentiated social systems", Pacific Sociological Review, 24, 4, 1981, pp. 385-387.

76 DURKHEIM, La división ..., cit., pp. 181, 198-199, 202 у 341-342. 
La diversidad de las sociedades más densas encierra dos fuerzas sociales contrapuestas, antagónicas que se compensan ${ }^{77}$. Por un lado, favorecen la individualización y debilitan la solidaridad en el sentido que acaba de decirse; por otro lado, aumentan la solidaridad porque cada individuo depende cada vez más de los demás. El sistema social se sostiene ahora como un organismo animado en el que los órganos son independientes entre sí, pero en el que al mismo tiempo unos dependen de otros para subsistir. DURKHEIM denomina a este tipo solidaridad orgánica ${ }^{78}$.

La solidaridad orgánica, característica de sociedades avanzadas como las nuestras, ya no se basa en unas ideas y sentimientos comunes, sino en nuevas instituciones de diversa naturaleza y sus relaciones entre ellas; a la par que permite crecer la autonomía de los individuos, que ya no están complemente envueltos y absorbidos por pequeñas unidades sociales. Como he adelantado, la conciencia individual se libera parcialmente mientras la colectiva se debilita. Ni que decir tiene, eso sí, que la conciencia colectiva conserva en todo caso una importancia nuclear $^{79}$.

A efectos ilustrativos, BERNSTEIN ofrece un ejemplo en el ámbito de la educación escolar del paso de un sistema de solidaridad mecánica a otro de solidaridad mecánica. Este autor señala que el control social en el colegio cambia con el paso de una forma de solidaridad a otra: de una transmisión de valores comunes a una confrontación de los alumnos como individuos; de un equipo escolar reducido a otro amplio con una mayor división del trabajo; de unos grupos fijos como la clase a una organización más flexible; de una pedagogía basada en el aprendizaje de elementos concretos relativos a contextos particulares a otra en la que se destacan los medios a través de los cuales se crea el conocimiento; de una educación en profundidad a otra en exten-

77 DURKHEIM, La división..., cit., pp. 53, 323 y 333-334.

78 DURKHEIM, La división ..., cit., pp. 131-154, 175-176, 181, 198-199, 202, 205-206, 216-217, 267-270, 341-342, 400 y 404.

79 DURKHEIM, La división ..., cit., p. 205. 
sión; e incluso de escuelas arquitectónicamente cerradas a otras abiertas en las que se ve el interior y se aceptan visitas. Como resultado del paso a una solidaridad orgánica, señala BERNSTEIN, la relación entre profesor y alumno adquiere una forma más individualizada y menos jerárquica y el rol de los alumnos en particular está cada vez menos definida. En conclusión, puesto que todos dependen unos de otros, en las nuevas escuelas existiría una mayor flexibilidad ${ }^{80}$.

Aunque se han visto realidades paradigmáticamente diferentes en ambos tipos de solidaridad mecánica y orgánica ${ }^{81}$, DURKHEIM sostiene no sólo que pueden coexistir, sino que la solidaridad orgánica no puede aparecer si no existe previamente solidaridad mecánica ${ }^{82}$. Por ejemplo, que un barrio goce de eficacia colectiva - una versión o dimensión de la solidaridad orgánica- o por el contrario sufra violencia y criminalidad puede depender del grado de confianza -solidaridad mecánica- que existiera en un momento histórico previo, al margen de la densidad social de dicho barrio.

La estructura social implica la existencia de ciertas posiciones y determina los contactos de quienes ocupan dichas posiciones entre sí -quiénes interaccionan entre sí, bajo qué condiciones, etc.-, al margen completamente de quiénes sean las personas concretas que ocupan dichas posiciones. Desde este punto de vista, la diferenciación de que habla DURKHEIM se refiere a cómo se distribuyen los individuos en posiciones sociales. BLAU divide la diferenciación en desigualdad, cuando aquélla se refiere a posiciones con diferencias jerárquicas, como las derivadas de la clase social y heterogeneidad, en otro caso, como ocurre con la religión, a la par que cree que las diferenciaciones pueden ser continuas o categóricas ${ }^{83}$. Si la estructura

80 BERNSTEIN, B., Class, codes and control, 3. Towards a theory of educational transmission, London: Routledge and Kegan Paul, 1975, pp. 67-73.

81 JENKS, Subculture..., cit., p. 25.

82 DURKHEIM, La división ..., cit., pp. 323-325.

83 BLAU, P. M., Inequality and heterogeneity. A primitive theory of social structure, New York: The Free Press, 1977, pp. 3-4, 8-11 y 45-99. 
emerge de interacciones y a la vez influye en éstas, la diferenciación abre oportunidades para unas interacciones y coloca barreras para otras ${ }^{84}$.

Un elemento clave de la teoría durkheimiana es la densidad moral ${ }^{85}$, que en su dimensión más básica se refiere sencillamente al número de personas que se concentran en un espacio físico de un cierto tamaño -lo cual determina las interacciones entre aquellas ${ }^{86}$. La densidad social, por lo tanto, depende básicamente del tamaño de la población, de la tasa de natalidad/ mortalidad y de los movimientos migratorios por un lado; de los medios de transporte y comunicación; y, en consecuencia, de la distribución y concentración de la población a lo largo del territorio ${ }^{87}$. La densidad social determina la estructura social; de modo que alteraciones en la primera se traducen en cambios en la segunda ${ }^{88}$. El aumento de la densidad tiene la consecuencia de que se eleva igualmente la lucha por la supervivencia - un argumento darwiniano ${ }^{89}-$, de modo que los individuos se ven forzados a competir por recursos, por prestigio ${ }^{90}$, etc. La división del trabajo social debida a la presión social es el resultado de este proceso complejo; y es la división del trabajo a la

84 BLAU, Inequality and heterogeneity..., cit., p. 10.

85 DURKHEIM, La división ..., cit., pp. 300 y 306; el mismo, -Nota sobre la morfología social-, en Las reglas del método sociológico y otros escritos sobre filosofia de las ciencias sociales (trad. S. González Noriega), Madrid: Alianza, 1897-1898/2000, p. 247.

86 GIDDENS, A., Durkheim, Glasgow: Fontana/Collins, 1978, p. 27.

87 BLAU, Inequality and heterogeneity ..., cit., pp. 160-166; DURKHEIM, La división, cit., pp. 301-304.

88 En particular, DURKHEIM conjetura que a mayor densidad social, mayor diferenciación social. Esta proposición tiene la forma de una ley, algo que caracteriza la postura de nuestro autor, DURKHEIM, La división ..., cit., p. 39.

89 DURKHEIM, La división ..., cit., pp. 311-318. Sobre e impacto de Darwin en las ciencias sociales de su tiempo, vid. JENKS, C., Culture, 2. ${ }^{a}$ ed. London y New York: Routledge, 2005, pp. 30-31.

90 PARSONS, por ejemplo, mantiene que la competición entre individuos debe verse sobre todo en términos de prestigio social y de satisfacción de la ambición, y no de subsistencia física, The structure of social action..., cit., p. 323. 
par lo que genera solidaridad (orgánica) ${ }^{91}$. Aunque los motivos de esta conexión causal no quedan completamente claros en DURKHEIM $^{92}$, deben relacionarse con un proceso de autoselección quizá conectado con una forma adecuada de cumplir la función de mantenimiento del grupo ${ }^{93}$.

Volveremos sobre este punto, si bien debe conservarse en mente que en Criminología tienen una gran aceptación las transiciones macroestructurales a micro. Por ejemplo, BROOKSGUNN y sus asociados estudian la conexión entre la estructura y el desarrollo individual a través de las características del barrio donde se reside y las respuestas de la familia a estas condiciones ${ }^{94}$; CRUTCHFIELD y WADSWORTH la influencia del barrio sobre el comportamiento juvenil, incluyendo el delictivo, a través del mercado laboral, el empleo juvenil y la experiencia laboral de los padres ${ }^{95}$.

Terminamos con unas últimas observaciones:

a. Llevado a una posición pura, esta tesis puede llevar a explicaciones estructuralistas en las que los individuos no desempeñan ningún rol ${ }^{96}$. Hechos macro son explicados mediante

91 DURKHEIM, La división ..., cit., pp. 65-66 y 71.

92 Ya que, por ejemplo, esta misma situación podría dar lugar sencillamente a la eliminación de parte de la población, PARSONS, The structure of social action..., cit., p. 323.

93 TURNER, -Émile Durkheim's theory of social organization-, cit., pp. 1091 y 1095-1096.

94 BROOKS-GUNN, J., G. J. DUNCAN, T. LEVETHAL y J. L. ABER, "Leasons learned and future directions for research on the neighborhoods in which children live", en Neighborhood poverty, 1. Context and consequences for children (J. BROOKS-GUNN et al. eds.), New York: Russell Sage Foundation, 1997, pp. 281-282.

95 CRUTCHFIELD, R. D. y T. WADSWORTH, "Aggravated inequality. Neighborhood economics, schools, and juvenile delinquency", en Economics and youth violence. Crime, disadvantage, and community (R. ROSENFELD et al. eds.), New York y London: New York University Press, 2013, pp. 152-153.

96 BLAU, Inequality and heterogeneity..., cit., p. 3. Vid. así mismo DURKHEIM, La división ..., cit., pp. 389 y 466. 
otros hechos macro. Aunque esta postura es lícita y quizá sea la esencia de la Sociología ${ }^{97}$, a mi juicio no representa la tesis durkheimiana, en la que aparece tanto lo agregado o social como lo individual ${ }^{98}$. En realidad, se ha visto una evolución en su pensamiento desde el primer polo del primer DURKHEIM hacia el segundo del DURKHEIM tardío ${ }^{99}$, si bien aquí tratamos de integrar ambos puntos de vista siguiendo siempre a la literatura ${ }^{100}$.

b. En ciencias sociales encontramos una amplia gama de posturas: desde los que rechazan que exista una estructura ${ }^{101}$; a quienes niegan que haya una cultura independiente, esto es algo más que una mera consecuencia de la estructura ${ }^{102}$; pasando por quienes proponen una especie de integración y ver, verbigracia, la estructura como cultura ${ }^{103}$.

97 MAYHEW, "Structuralism versus individualism: Part 1...”, cit., pp. 339340 y 346; el mismo, "Structuralism versus individualism: Part 2, Ideological and other obfuscations", Social Forces, 59, 3, 1981, pp. 637-640.

98 SERRANO MAÍlLO, Firmeza, cit., p. 255. PORPORA sostiene, por el contrario, que la postura durkheimiana sobre la estructura concebiría ésta (únicamente) como regularidades con forma de ley, de lo cual se excluiría cualquier rol para la agencia o una dimensión de patrones estables, PORPORA, D. V., "Four concepts of social structure", Journal for the Theory of Social Behavior, 19, 2, 1989, pp. 197-198; a la par que critica esta postura, p. 203; el mismo, Reconstructing Sociology. The critical realist approach, Cambridge: Cambridge University Press, 2015, pp. 42-45. Una contestación en SAWYER, R. K., Social emergence. Societies as complex systems, Cambridge [etc.]: Cambridge University Press, 2005, p. 85.

99 TURNER,-Émile Durkheim's theory of social organization-, cit., pp. 1090.

100 Vid. SAWYER, Social emergence ..., cit., pp. 100-124 y 210-230; TURNER, "Émile Durkheim's theory of integration in differentiated social systems", cit., pp. 381-387; el mismo, "A behavioral theory...", cit., pp. 358362; el mismo, -Émile Durkheim's theory of social organization-, cit., pp. 1093-1102.

101 SELLIN, T., Culture conflict and crime, New York: Social Science Research Council, 1938, pp. 26-27.

102 WACQUANT, L. J. D. y W. J. WILSON, "The cost of racial and class exclusion in the inner city", en The Annals of the American Academy of Political and Social Sciences, 501. The ghetto underclass: Social science perspectives (W. J. WILSON ed.), 1989, p. 25.

103 MILLER, W., en W. C. KVARACEUS et al., Delinquent behavior. Culture and the individual, Washington, DC: National Education Association of the 
c. La agencia puede verse como un tercer elemento junto a estructura y cultura, si bien aquí se toma como un elemento residual que pueden entrar como explicación cuando se agoten las anteriores -de modo que idealmente es un factor redundante ${ }^{104}$. En este sentido, la acción puede influir en la estructura y no sólo al revés ${ }^{105}$.

Finalmente, un problema muy serio que afrontan las hipótesis sobre efectos macro-a-micro -que aquí asumimos, sin embargo, en nuestro enfoque durkheimiano-, en particular en el marco de modelos estructurales, es el de la selección. Por ejemplo, se puede hipotetizar que determinadas características de los barrios ejercen una influencia sobre el comportamiento de sus habitantes -causación social. Aunque esto es plausible, cabe preguntarse si no podría ser más bien que los individuos no pueblan un barrio u otros de modo aleatorio -o sea que se han seleccionado-, de modo que podrían ser sus particularidades y conductas las que, agregadas, arrojarían determinadas características de los barrios-selección causal-, lo cual también puede asumirse.

Puesto que es el que más habitualmente se plantea en Criminología, puede decirse que es un problema de difícil solución desde un punto de vista empírico dadas las limitaciones habitualmente existentes en ciencias humanas y sociales ${ }^{106}$. Así, ROSENFELD y sus colegas conceden que, aunque se han empleado

United States, 1959, p. 139; el mismo, "The impact of a 'total community' delinquency control project”, Social Problems, 10, 1962, p. 169.

104 En contraste, movimientos actuales le conceden un rol mayor a la agencia, vid. PORPORA, Reconstructing Sociology..., cit., p. 128.

105 ANDERSON, E., A place on the corner, Chicago y London: The University of Chicago Press, 1976, pp. 51 y 216; el mismo, Code of the street. Decency, violence, and the moral life of the inner city, New York y London: W.W. Norton, 1999, p. 296.

106 FANG, X., R. ROSENFELD, L. L. DAHLBERG y C. S. FLORENCE, “The nonlinear effect of neighborhood disadvantage on youth violence. Neighborhood effects on youth violence", en Economics and youth violence. Crime, disadvantage, and community (R. ROSENFELD et al. eds.), New York y London: New York University Press, 2013, p. 122. 
diversos enfoques metodológicos para tratar esta cuestión -diseños transversales con controles, quizá multinivel; diseños longitudinales que siguen a individuos o comunidades a lo largo del tiempo; y modelos relativamente sofisticados de nivelación del grado de propensión-, nunca es posible eliminar completamente un sesgo de selección ${ }^{107}$.

Por lo tanto, una cuestión básica es ¿qué es más importante, la causación social o la selección causal? La causación social ve en la conducta individual un resultado de influencias agregadas - $\mathrm{O}$ sea que propugna mecanismos macro-a-micro-; la selección causal ve en los elementos agregados de una comunidad un resultado de las conductas individuales $-\mathrm{o}$ sea mecanismos micro-a-macro. Si, por ejemplo, la teoría general del delito o del autocontrol favorece el segundo mecanismo ${ }^{108}$, en la literatura parece prevalecer el primero. Como he defendido con más detalle otro lugar ${ }^{109}$, el problema, por el contrario, es si es posible ofrecer una teoría unificadora de variables y explicaciones macro y micro a la vez y que ambos niveles gocen del mismo peso, o sea que sean insesgados o iguales $^{110}$. En el estricto terreno empírico se mantienen las dificultades para establecer efectos contextuales. En el plano teórico, SAMPSON ${ }^{111}$ y WIKSTRÖM y sus colegas ${ }^{112}$ ofrecen el siguiente argumento: "la selección es mucho más que un incordio estadístico [...]

107 ROSENFELD et al., "Introduction”, cit., p. 18.

108 GOTTFREDSON, M. R. y T. HIRSCHI, A general theory of crime, Stanford, Ca.: Stanford University Press, 1990, pp. 166-168.

109 SERRANO MAÍLLO, A., El problema de las contingencias en la teoría del autocontrol. Un test de la teoría general del delito, 2. ${ }^{\text {a }}$ ed., Madrid: Dykinson, 2013, pp. 405-414.

110 HIRSCHI, T., The craft of Criminology. Selected papers (J. LAUB ed.), New Brunswick, NJ y London: Transaction Publishers, 2002, p. 257.

111 SAMPSON, R. J., Great American city. Chicago and the enduring neighborhood effect, Chicago [etc.]: University of Chicago Press, 2012, pp. 288290 y 308.

112 WIKSTRÖM, P.-O. H., D. OBERWITTLER, K. TREIBER y B. HARDIE, Breaking rules. The social and situational dynamics of young people's urban crime, Oxford: Oxford University Press, 2012, p. 38. 
[ofrecemos] una visión alternativa que invoca a la vez el poder de la estructura y de la elección -"cadenas de selección"“, "incluso aquí el contexto importa: la gente se muda por una serie de razones, pero raramente son características de los barrios de origen y destino irrelevantes en las evaluaciones cognitivas [...] el sesgo de selección es él mismo una forma de efecto del barrio" ${ }^{113}$. Este planteamiento, sin embargo, no resuelve desde un punto de vista teórico cómo es que todas las diferencias individuales -en términos no sólo de autocontrol sino también de capital social, capacidad individual, etc.- son irrelevantes a la hora, verbigracia, de cambiar de barrio; y desde una perspectiva empírica tampoco controla de modo exhaustivo las diferencias individuales, con la consecuencia de que no puede excluir que parte de los efectos situacionales no sean realmente efectos individuales ${ }^{114}$.

\section{Patrones culturales}

\subsection{Cultura: un enfoque durkheimiano}

En la tradición de DURKHEIM, la cultura tiene un carácter social ${ }^{115}$. Aquí entenderemos cultura como sistema de símbolos y significados ${ }^{116}$. GEERTZ define la cultura como "un patrón transmitido históricamente de significados encapsulados en símbolos, un sistema de concepciones heredadas expresadas

113 SAMPSON, Great American city..., cit., pp. 288 y 308, énfasis eliminado. 114 JENCKS y MAYER, “The social consequences...”, cit., pp. 173-181.

115 SUTHERLAND y sus colegas insisten en el carácter social de los procesos y patrones que estudian, pero su visión de la cultura tiene una naturaleza al menos en parte espacial, SUTHERLAND et al., Principles of Criminology, 11. ${ }^{\text {a }}$ ed., cit., p. 202.

116 ALEXANDER, J. C., "The promise of a cultural sociology: technological discourse and the sacred and profane information machine", en Theory of culture (R. MÜNCH y N. J. SMELSER eds.), Berkeley [etc.]: University of California Press, 1992, p. 295; JENKS, Culture, cit., p. 60; PARSONS, T., Social systems and the evolution of action theory, New York: The Free Press, 1977, p. 168. Sobre la evolución de esta tradición, particularmente en Antropología, vid. JENKS, Culture, cit., pp. 34-38 y 40-42. 
en formas simbólicas a través de los cuales los hombres comunican, perpetúan y desarrollan su conocimiento sobre la vida y sus actitudes hacia ella"; "un sistema ordenado de significado y símbolos $[\ldots]$ en virtud del cual los individuos definen su mundo, expresan sus sentimientos y hacen sus juicios"117. Los símbolos, que pueden ser cualquier cosa, evocan en nuestras sociedades algo invisible pero real y compartido y hacen posible la representación y el significado ${ }^{118}$.

Entendida de este modo, la cultura está compuesta por comprensiones y significados que no son individuales ni privados sino compartidos y públicos; a la par que abarca acciones, creencias, ritos. No es un poder causal, algo que por sí mismo inicie una acción o permita una explicación etiológica, ni tampoco una caja de herramientas o estrategias ${ }^{119}$; sino un marco o contexto para la comprensión de la vida y del mundo ${ }^{120}$. Así, la cultura permite tipificar y evaluar; en la afortunada frase de DOUGLAS, la cultura media nuestra experiencia ${ }^{121}$. Cuando un individuo se enfrenta con una nueva vivencia espera que se trate de una categoría típica del mundo tal y como lo comprende. Por muy novedosa y extraña que sea, sólo existe un número limitado -y socialmente construido- de categorías para clasificarla y por lo tanto esperamos que nuestro sistema taxonómico dé cuenta de la misma ${ }^{122}$. Estos sistemas clasificatorios, agrupatorios de expe-

117 GEERTZ, C. The interpretation of cultures. Selected essays, New York: Basic Books, 1973, pp. 89 y 144. Críticamente con el enfoque aquí patrocinado, SWIDLER, A., Talk of love. How culture matters, Chicago y London: The University of Chicago Press, 2001, pp. 19-23.

118 RAWLS, A. W., Epistemology and practice. Durkheim's The elementary forms of religious life, Cambridge [etc.]: Cambridge University Press, 2004 , pp. 39-40, 143-146, 166, 168, 180, 224 y 273-275.

119 SWIDLER, A., "Culture in action: symbols and strategies", American Sociological Review, 51, 1986, pp. 273 y 276-282; la misma, Talk of love..., cit., pp. 24-40.

120 JENKS, Culture, cit., p. 61.

121 DOUGLAS, M., Purity and danger. An analysis of concept of pollution and taboo, London y New York: Routledge, 1966/1984, pp. 40 y 129.

122 DURKHEIM, E. y M. MAUSS, Primitive classification (R. Needham trad.), London: Cohen and West, 1903/1969, pp. 2-5. 
riencias son simbólicos, en cuanto que deben ser abstracciones. Como correlato, estas tipificaciones son igualmente imprescindibles para comunicarse y entenderse recíprocamente con otros individuos ${ }^{123}$. En segundo lugar, la cultura permite evaluaciones de las experiencias por ejemplo mediante esquemas cognitivos y emocionales de una dicotomía como es el bien y el mal.

Como acaba de decirse, mediante la cultura, los actores pueden explicarse el mundo y comunicarse utilizando el sistema compartido de símbolos y significados: aquélla constituye un sistema o complejo que funciona como "fuentes extrínsecas de información"124. La cultura, finalmente, es aprendida a través del proceso de socialización ${ }^{125}$.

\subsection{La cultura en la Criminología etiológica mayori- taria contemporánea: valores y subculturas}

En Criminología existe una gran imprecisión sobre qué se entiende por cultura -así como términos derivados como subcultura. En algunos estudios parece que existe una única cultura en un país; en otros da la impresión de que se cruza una calle y se cambia de cultura ${ }^{126}$; mientras que algunos más parecen sugerir que en un mismo lugar pueden coincidir varias culturas de modo simultáneo.

Siguiendo a la literatura ${ }^{127}$, puede entenderse que en un país o región o bien en un grupo social amplio y heterogéneo tenderá a existir una única cultura, que en nuestra disciplina a veces se ve como dominante o generatriz -esto ocurre en los

123 RAWLS, Epistemology and practice..., cit., pp. 1-3 y 39.

124 GEERTZ, The interpretation..., cit., p. 92.

125 DURKHEIM, E., Education and Sociology (trad. S. D. Fox), New York: The Free Press, 1925/1956, pp. 61 y 64-65; PARSONS, T., The social system, New York: The Free Press, 1951, pp. 11-12, 16, 34-37 y 226-243.

126 Como en el caso de STEWART y SIMONS, "Race, code of the Street...", cit., pp. 575-576 y 579 .

127 CURTIS, L. A., Violence, race, and culture Lexington, Mass. [etc.]: Lexington, 1975, pp. 7-9; YINGER, J. M., "Contraculture and subculture", American Sociological Review, 25, 5, 1960, pp. 625-633. 
enfoques subculturales. El motivo de que exista una única cultura es que de otro modo sería difícil la comunicación entre los miembros de ese grupo, no digamos ya una mínima cohesión que permitiera su unión. Por poner un ejemplo, SANEY, que adopta un enfoque cultural para explicar las altas tasas de criminalidad de Estados Unidos ${ }^{128}$, afirma que "las normas y valores que abarcan el panorama del mundo [norte]americano contemporáneo $[\ldots]$ influyen de manera indirecta en la naturaleza de la estructura social y del comportamiento individual en todas las situaciones de la vida" 129 .

Según MILLER, existen tres conexiones entre cultura y delito: en ocasiones, ciertas prácticas culturales son en sí mismas delictivas; otras veces caben tanto opciones lícitas como ilícitas, pero estas últimas son más ventajosas ya que permiten obtener algo más rápidamente y con menos esfuerzo; finalmente, la cultura exige una respuesta a ciertas situaciones que implica la comisión de algún delito ${ }^{130}$.

Los valores son la base de las teorías subculturales ${ }^{131}$. Una subcultura contiene algunos valores distintos de los dominantes, pero no están en conflicto con ellos. Puede asumirse que existen subculturas en la actualidad y un ejemplo puede encontrarse en grupos de niños e incluso adolescentes ${ }^{132}$. Si bien la subcultura suele relacionarse en nuestra disciplina con la desviación y el delito, existen subculturas en las que predomina lo prosocial ${ }^{133}$. En este sentido, una subcultura no tiene que ser algo necesa-

128 SANEY, P., Crime and culture in America. A comparative perspective, New York [etc.]: Greenwood, 1986, pp. 10, 12 y 47-86.

129 SANEY, Crime and culture..., cit., p. 6.

130 MILLER, W., "Lower class culture as a generating milieu of gang delinquency", The Journal of Social Issues, 14, 3. New light on delinquency (W. MCCORD ed.), 1958, p. 18.

131 BALL-ROKEACH, S. J., "Values and violence: A test of the subculture of violence thesis", American Sociological Review, 38, 6, 1973, p. 737.

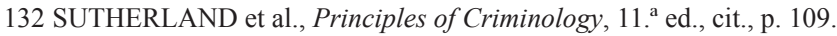

133 ANDERSON, E., Streetwise. Race, class, and change in an urban community, Chicago y London: The University of Chicago Press, 1990, pp. 12-21. 
riamente inferior a una cultura más amplia puesto que grupos artísticos avanzados han sido definidos como subculturas ${ }^{134}$. Las subculturas tampoco se confunden con las bandas, si bien existen teorías criminológicas que así lo han hecho ${ }^{135}$. DOWNES ${ }^{136}$ distingue dos tipos de subculturas: las que se forman fuera de una cultura dominante, como en el caso de grupos inmigrantes que llegan a un nuevo país; y las que se forman dentro de una cultura dominante ya sea como una respuesta positiva -grupos de adolescentes, miembros de una profesión...- o negativa subculturas criminales, grupos políticos o religiosos radicales o extremistas... Por el contrario, una contracultura tiene valores distintos de los dominantes, que al mismo tiempo están en conflicto con estos segundos. Que existan subculturas no implica, como veremos, que existan subculturas delictivas ni que los valores sean una causa de la criminalidad.

\subsection{El sesgo anticultural de las ciencias sociales con- temporáneas}

Puede hablarse tranquilamente de un sesgo anticultural en las ciencias sociales y en la Criminología etiológica mayoritaria contemporánea en concreto ${ }^{137}$. Aunque casi por norma se relaciona la cultura con algo negativo, coercitivo, opresor ${ }^{138} \ldots$, uno de cuyos ejemplos más conocidos es la llamada cultura del control propuesta por GARLAND ${ }^{139}$, la esencia de la cultura y

134 PARSONS, The social system, cit., pp. 411-412.

135 DOWNES, D., The delinquent solution: A study in subcultural theory, London: Routledge, 1966, p. 12.

136 DOWNES, The delinquent solution ..., cit., p. 9.

137 BOURGOIS, P., In search of respect. Selling crack in El Barrio, Cambridge [etc.]: Cambridge University Press, 1995, pp. 318 y 232; SULLIVAN, M. L., "Getting paid". Youth crime and work in the inner city, Ithaca y London: Cornell University Press, 1989, p. 242.

138 TONRY, M., Punishment and politics. Evidence and emulation in the making of English crime control policy, Cullompton, Devon: Willan Publishing, 2004, p. 64.

139 Un editor anónimo me ha advertido que la afirmación de un sesgo anticultural, en el mejor de los casos, no es extensible al estudio criminológico de la 
de los mecanismos culturales es ofrecer protección a los individuos ${ }^{140}$.

En segundo lugar, no sólo predominan las críticas a las teorías culturales y subculturales -a menudo in toto-, incluidas las de tipo ideológico ${ }^{141}$; sino que además se les presta poca atención ${ }^{142}$. Esta actitud crítica es resumida por AEBI cuando escribe, desde las antípodas de nuestro planteamiento durkheimiano ${ }^{143}$, que "sólo hay seres humanos"144. Más acerado, WACQUANT acusa a uno de los enfoques culturales más influyentes en la actualidad, el del código de la calle, de adoptar "una posición culturalista con implicaciones políticas profundamente perturbadoras en cuanto que hace responsables a los habitantes del gueto de su propia situación apurada a causa de sus valores desviados o de la ineptitud de sus roles"145.

penalidad. Un buen ejemplo de esta presencia de la cultura en algunos ámbitos o quizá paradigmas de nuestra disciplina es la llamada Criminología cultural, la cual revisa la relación entre la cultura entendida en un sentido muy amplio y la criminalización. Adopta una orientación conflictual en la que una elite de poderosos define qué es criminal y qué no lo es, incluso en casos que son equivalentes según los investigadores; al tiempo que rechaza las metodologías cuantitativas. La Criminología cultural también estudia el rol de los medios de comunicación en el proceso de criminalización. A su juicio existiría un proceso de criminalización de base cultural que decide qué es delito y qué no lo es sin limitaciones en la práctica; el delito no existiría en sí mismo, al margen de procesos de base cultural. Vid., sobre todo ello, FERRELL, J., K. HAYWARD y J. YOUNG, Cultural Criminology: An invitation, London [etc.]: Sage, 2008, pp. 1-24; PRESDEE, M., Cultural Criminology and the carnival of crime, London y New York: Routledge, 2000, pp. 17-30.

140 SERRANO MAÍLLO, Firmeza ..., cit., p. 466.

141 Advertido ya por SURRATT, H. L., J. A. INCIARDI, S. P. KURTZ y M. C. KILEY, "Sex work and drug use in a subculture of violence", Crime and Delinquency, 50, 1, 2004, p. 44.

142 HOROWITZ, R., Honor and the American dream. Culture and identity in a Chicano community, New Brunswick, NJ: Rutgers University Press 1983, p. 15.

143 DURKHEIM, El suicidio..., cit., p. 337.

144 AEBI, M., Temas de Criminología, Madrid: Dykinson, 2008, p. 73.

145 WACQUANT, L., "Scrutinizing the street: Poverty, morality, and the pitfalls of urban Ethnography", American Journal of Sociology, 107, 6, 2002, p. 1500 , vid. también pp. 1521 y 1527. 
Esta asimetría valorativa entre estructura y cultura se manifiesta en los siguientes comentarios de WACQUANT y J. WILSON: "han creado una división normativa ficticia entre las personas de color de las ciudades que, al margen de su realidad [...] sólo puede palidecer cuando se la compara a la brecha estructural objetiva que separa a los residentes del gueto de la sociedad general y a los constreñimientos materiales colectivos que pesan sobre ellos", para concluir con que "si se utiliza el concepto de infraclase, debe ser un concepto estructural [...] No debe ser utilizado como etiqueta para designar una nueva raza (breed) de individuos moldeados libremente por una cultura de la pobreza mítica y todopoderosa"146. Dejando de lado que la cultura también es objetiva en cuanto que compartida y se impone a los individuos igual que la estructura; y dejando de lado que estructura y cultura se encuentran íntimamente relacionadas y en ningún caso son elementos autónomos cuando no contrapuestos; en este artículo valoramos las investigaciones por sus méritos científicos y no por sus supuestas consecuencias ideológicas. Una teoría estructural y otra cultural deben competir entre sí siguiendo ciertos criterios de carácter empírico, y no es posible -aunque sí cómodo- decidir a favor de uno de ellos de modo apriorístico por razones ideológicas.

Finalmente, cultura y estructura a menudo se tratan en Criminología como entidades independientes y casi opuestas entre $\mathrm{si}^{147}$-cuando aquí las hemos considerado diferentes únicamente desde un punto de vista analítico, no ontológico.

Las críticas científicas son legítimas, pero tienen por delante el difícil reto de afrontar preguntas criminológicamente relevantes sin recurrir a la cultura -en particular en su versión simbólica de base durkheimiana. Así, HOROWITZ afirma en relación con la comunidad de chicanos que estudia que las "ex-

146 WACQUANT y WILSON, “The cost...-, cit., p. 25 (énfasis añadido).

147 OUSEY, G. C. y P. WILCOX, "Subcultural values and violent delinquency. A multilevel analysis in middle schools", Youth Violence and Juvenile Justice, 3, 1, 2005, p. 5. 
plicaciones estructurales de las diferencias son insuficientes en cuanto que no pueden explicar diferencias culturales entre grupos que ocupan prácticamente el mismo estatus socioeconómico"; y que existen elementos culturales que no se alteran incluso aunque cambie la posición estructural del grupo; a la par que abunda en que las mismas desigualdades estructurales no son vividas, experimentadas del mismo modo por grupos distintos ${ }^{148}$.

\section{Procesos delictivos}

Más arriba he definido los procesos como un fenómeno dinámico con varias fases y referido de modo más directo a la biografía de las personas y grupos de los que forman parte; al tiempo que son igualmente hechos. Sutherland afirma que existen varios sentidos en los que se utiliza el término procesos sociales en las ciencias sociales, pero en su exposición destaca que a todos ellos subyace la idea de heterogeneidad: «un amplio rango de hechos y secuencias de eventos, acciones y situaciones», «características específicas [que], cuando están presentes, se combinan con otras características y situaciones», «un complejo sistema de antecedentes» ${ }^{149}$. También aquí le concedemos esta orientación amplia y heterogénea al concepto de proceso -que a continuación genera de modo emergente procesos.

Los procesos delictivos pueden dividirse en tres grandes grupos: biográficos; de socialización y crianza; y de grupo. Entre las variables o patrones biográficos se incluyen el sexo; la edad; características físicas y mentales como la personalidad, la inteligencia, la constitución física, el autocontrol, etc.; el estatus inmigración, que ciertamente es un concepto muy amplio que requiere ser desagregado; la clase social y el estatus socioeconómico; la moralidad (individual) tanto en su dimensión cognitiva como en la emocional; o el empleo. Figuras más genéricas como

148 HOROWITZ, Honor and the American dream..., cit., pp. 27, de donde procede la cita, 31 y 234.

149 SUTHERLAND, The Sutherland papers, cit., pp. 113-115. 
las carreras criminales o la predicción o evaluación del riesgo de criminalidad o reincidencia también se encuadran en este punto.

Los procesos de socialización y crianza incluyen a la familia -la crianza, la criminalidad y experiencia en el Sistema de Administración de Justicia de padres, hermanos y otros familiares, el conflicto familiar, el maltrato y la violencia, los hogares rotos, etc.--, a la escuela, a los mentores y al matrimonio, la vida en pareja y la descendencia.

Por último, procesos de grupo son los pares y los procesos de asociación diferencial en general, la codelincuencia, las redes, la delincuencia organizada y las bandas delincuentes, muchas de ellas de jóvenes.

\section{Conclusiones}

Sutherland consideraba que una generalidad de los conceptos que utilizamos en ciencias sociales era imprecisos, de modo que «no es sabio estar limitado por ellos», y menciona los procesos sociales como un ejemplo de este estado de $\operatorname{cosas}^{150}$. Al mismo tiempo, la discusión y el avance científicos difícilmente pueden darse bajo condiciones de ambigüedad ${ }^{151}$. La investigación sobre patrones y procesos delictivos tiene en gran medida un carácter descriptivo ${ }^{152}$. Por eso es comprensible la relativa falta de atención a aspectos causales de muchos procesos ${ }^{153}$. Incluso cuando existe una preocupación causal se echa de menos la teorización previa que permita derivar hipótesis, orientar la investigación y proponer controles relevantes ${ }^{154}$. Más en general, una orientación inductiva parece dominar el estudio de los

150 SUTHERLAND, The Sutherland papers, cit., pp. 112.

151 DURKHEIM, Las reglas..., cit., p. 62.

152 Así, BUSHWAY, S., P. J. COOK y M. PHILLIPS, "The net effect of the business cycle on crime and violence", cit., p. 48.

153 BOX, S., Recession, crime and punishment, Houndmills y London: MacMillan, 1987, pp. 68 y 75; ROSENFELD et al., "Introduction", cit., p. 6.

154 CRUTCHFIELD y WADSWORTH, “Aggravated inequality...,", cit., p. 152. Vid., con detalles y en conexión con uno de los temas básicos de este 
patrones y procesos delictivos. Esto puede verse por ejemplo en los contrastes de hipótesis interactivas, de las que a menudo no se ofrece ya una justificación teórica, sino una argumentación que no sea puramente ad hoc del signo de los coeficientes; mientras que las conjeturas de mediación a veces van introduciendo variable tras variable a ver qué encuentran.

Una observación habitual es que el delito es un fenómeno tan heterogéneo que, igual que no sería plausible construir explicaciones generales a nivel individual, tampoco debe serlo proponer patrones y procesos generales para todas las modalidades. Intuitivamente se puede pensar en delitos violentos y contra el patrimonio. Como he defendido en otros lugares, los enfoques generales son preferibles en igualdad de condiciones a los tipológicos, que además tienen que afrontar ellos mismos unos problemas metodológicos formidables ${ }^{155}$. Igual que a nivel individual la versatilidad es un argumento muy sólido contra las tipologías, existen pruebas a nivel agregado de una conexión entre delito contra el patrimonio y violencia, una conexión que podría ser incluso causal ${ }^{156}$. Por ejemplo, BAUMER y sus colegas, con datos de 82 ciudades norteamericanas, señalan una fuerte asociación entre la tasa de delitos contra la propiedad y la de homicidios, tanto para las tasas totales como para las limitadas a los cometidos por jóvenes, jóvenes adultos y adultos de homicidios ${ }^{157}$.

artículo, JENCKS, C. y S. E. MAYER, "The social consequences of growing up in a poor neighbourhood", en Inner-city poverty in the United States (L. E. LYNN y M. G. H. MCGEARY eds.), Washington, DC: National Academy Press, 1990, pp. 112-113, 118-121, 125, 130, 137, 154-162, 167 y 173-181.

155 SERRANO MAÍLLO, Introducción..., cit., pp. 211-215.

156 FARRINGTON, D. y R. LOEBER, "Early risk factors for convicted homicide offenders and homicide arrestees", en Young homicide offenders and victims. Risk factors, prediction, and prevention from childhood ( $\mathrm{R}$. LOEBER y D. FARRINGTON eds.), New York [etc.]: Springer, 2011, pp. 68-69; ROSENFELD et al., "Introduction", cit., p. 16. A los presentes efectos, no tiene mayor relevancia la naturaleza real de la relación entre ambas modalidades delictivas, una vez que la misma puede establecerse.

157 BAUMER, E., R. ROSENFELD y K. WOLFF, “Are criminogenic consequences of economic downturns conditional? Assessing potential modera- 
La advertencia metodológica esencial al hablar de patrones y procesos delictivos es que asociación o correlación no equivalen a causalidad. Los llamados factores de riesgo o concurrentes permiten predecir el delito y la criminalidad y algunos pueden ser causas del delito, pero establecer una correlación o un factor predictivo no implica causalidad ${ }^{158}$. Esta importante advertencia es ignorada casi sistemáticamente. Por supuesto, algunos estudios y sus hallazgos pueden tener una alta calidad metodológica por ejemplo según el Listado de Calidad de Cambridge ${ }^{159}$-que tiene en cuenta la adecuación de muestreo,

tors of the links between adverse economic conditions and crime rates", en Economics and youth violence. Crime, disadvantage, and community (R. ROSENFELD et al. eds.), New York y London: New York University Press, 2013, p. 66.

158 MURRAY y sus colegas plantean que los factores de riesgo sean universales, MURRAY, J., Y. SHENDEROVICH, F. GARDNER, C. MIKTON, J. DERZON, J. LIU y M. EISNER, "Risk factors for antisocial behavior in low- and middle- income countries: A systematic review of longitudinal studies", en Crime and Justice, 47, Chicago, Ill.: The University of Chicago Press, 2018, p. 334.

Un problema paralelo es que muchos estudios se limitan a reportar efectos bivariados, de modo que puede esperarse que desaparezcan cuando se controlen otras variables, PRATT, T. y F. CULLEN, "Assessing macro-level predictors and theories of crime: A meta-analysis", en Crime and Justice, 32 (M. TONRY ed.), Chicago, Ill.: The University of Chicago Press, 2005, p. 377. Aunque por supuesto no puede esperarse que variables que aparecen relativamente pronto en la vida de las personas conserven un impacto en comportamientos que tienen lugar muchos años más tarde -cuya relación será mediada en el caso típico-, las variables que deben controlarse son contemporáneas. Por ejemplo, en el estudio longitudinal de cohorte británico se encontró que un bajo cociente intelectual a la edad de 5 años predecía de modo robusto problemas de conducta a la edad de 10 años y condenas criminales entre los 16 y los 34 años (razón de las ventajas $\geq 1,5$ ), MURRAY, J., B. IRVING, D. FARRINGTON, I. COLMAN y C. BLOXSOM, "Very early predictors of conduct problems and crime: results from a national cohort study", Journal of Child Psychology and Psychiatry, 51, 11, 2010, p. 1202; la excepción eran las condenas de chicas entre los 16 y los 34 años. Sin embargo, cuando se recurre a modelos multivariantes con control de otros factores de riesgo, este carácter predictivo desaparece, p. 1203.

159 JOLLIFFE, D., J. MURRAY, D. FARRINGTON y C. VANNICK, “Testing the Cambridge Quality Checklists on a review of disrupted families and crime", Criminal Behavior and Mental Health, 22, 5, 2012, pp. 304-305. 
el tamaño muestral, el porcentaje de respuestas, el diseño, las correlaciones o la calidad de las medidas de variables dependientes-, pero eso no altera nuestra advertencia ${ }^{160}$.

Como conclusión de este trabajo centrado en la Criminología etiológica mayoritaria, la idea de patrones y procesos delictivos de SUTHERLAND parece prometedora para las dos misiones que les reservaba: contribuir a la organización y sistematización del conocimiento; y permitir una explicación del delito plausible y consistente con los hechos conocidos sobre el delito, esto es definitorios en su terminología. Puesto que tanto él como sus seguidores nos ofrecen más bien los mimbres de estos conceptos que una exposición sistemática, aquí he propuesto una reconstrucción a partir del trabajo del DURKHEIM de $L a$ división del trabajo social. La única discrepancia básica entre ambos enfoques es que una teoría criminológica difícilmente puede aspirar a ofrecer una explicación general de lo social -el ámbito en el que de modo contumaz se ubican SUTHERLAND y CRESSEY-, lo cual es consistente con que suelen tener un alcance medio ${ }^{161}$. Dicho con otras palabras y frente al planteamiento de estos últimos autores, desde un punto de visa metodológico se requiere un marco teórico (sociológico) más amplio sobre el que construir una teoría criminológica. Aquí me mantendré neutral sobre si DURKHEIM, a quien juzgo como un teórico del control sobre todo en su importante libro La educación moral (aproximadamente de 1902, aunque publicado póstumamente) ${ }^{162}$, puede ofrecer unos cimientos firmes para las teorías del aprendizaje, pero he tratado de defender que al menos sí los ofrece para esta brillante -y útil- propuesta de SUTHERLAND de patrones y procesos delictivos.

160 Vid. sobre este punto MURRAY, J., D. FARRINGTON y M. EISNER, "Drawing conclusions about causes from systematic reviews of risk factors. The Cambridge Quality Checklist", Journal of Experimental Criminology, 5, 2009, pp. 1-21.

161 SERRANO MAÍLLO, Introducción, cit., pp. 215-217. Sobre el concepto de teorías de alcance medio, MERTON, R. K., Social theory and social structure, edición ampliada, New York: The Free Press, 1968, pp. 68-69.

162 SERRANO MAÍLLO, El problema de las contingencias..., cit., pp. 55-56. 


\section{Bibliografía}

AEBI, M., Temas de Criminología, Madrid: Dykinson, 2008.

ALEXANDER, J. C., "The promise of a cultural sociology: technological discourse and the sacred and profane information machine", en Theory of culture (R. MÜNCH y N. J. SMELSER eds.), Berkeley [etc.]: University of California Press, 1992.

ALlER, G., Criminalidad del poder económico. Ciencia y praxis, Montevideo y Buenos Aires: BdeF, 2011.

ANDERSON, E., Code of the street. Decency, violence, and the moral life of the inner city, New York y London: W.W. Norton, 1999.

ANDERSON, E., Streetwise. Race, class, and change in an urban community, Chicago y London: The University of Chicago Press, 1990.

ANDERSON, E., A place on the corner, Chicago y London: The University of Chicago Press, 1976.

BALL-ROKEACH, S. J., "Values and violence: A test of the subculture of violence thesis", American Sociological Review, 38, 6, 1973.

BAUMER, E., R. ROSENFELD y K. WOLFF, “Are criminogenic consequences of economic downturns conditional? Assessing potential moderators of the links between adverse economic conditions and crime rates", en Economics and youth violence. Crime, disadvantage, and community (R. ROSENFELD et al. eds.), New York y London: New York University Press, 2013.

BERNSTEIN, B., Class, codes and control, 3. Towards a theory of educational transmission, London: Routledge and Kegan Paul, 1975.

BLAU, P. M., Inequality and heterogeneity. A primitive theory of social structure, New York: The Free Press, 1977.

BOURGOIS, P., In search of respect. Selling crack in El Barrio, Cambridge [etc.]: Cambridge University Press, 1995.

BOX, S., Recession, crime and punishment, Houndmills y London: MacMillan, 1987. 
BROOKS-GUNN, J., G. J. DUNCAN, T. LEVETHAL y J. L. ABER, "Leasons learned and future directions for research on the neighborhoods in which children live", en Neighborhood poverty, 1. Context and consequences for children (J. BROOKS-GUNN et al. eds.), New York: Russell Sage Foundation, 1997.

BUSHWAY, S. y P. REUTER, "Labor markets and crime", en Crime. Public policies for crime control (J. Q. WILSON y J. PETERSILIA eds.), Oakland, Ca.: ICS., 2002.

BUSHWAY, S., P. COOK y M. PHILLIPS, "The net effect of the business cycle on crime and violence", en Economics and youth violence. Crime, disadvantage, and community (R. ROSENFELD et al. eds.), New York y London: New York University Press, 2013.

COLLINS, R., Four sociological traditions, New York y Oxford: Oxford University Press, 1994.

CONNELL, R. Gender in world perspective, 2. ${ }^{\text {a }}$ ed., Cambridge y Malden, Mass.: Polity, 2009.

CRUTCHFIELD, R. D. y T. WADSWORTH, "Aggravated inequality. Neighborhood economics, schools, and juvenile delinquency", en Economics and youth violence. Crime, disadvantage, and community (R. ROSENFELD et al. eds.), New York y London: New York University Press, 2013.

CURTIS, L. A., Violence, race, and culture, Lexington, Mass. [etc.]: Lexington, 1975.

DOUGLAS, M., Purity and danger. An analysis of concept of pollution and taboo, London y New York: Routledge, 1966/1984.

DOWNES, D., The delinquent solution: A study in subcultural theory, London: Routledge, 1966.

DURKHEIM, E., Education and Sociology (trad. S. D. Fox), New York: The Free Press, 1925/1956.

DURKHEIM, E. y M. MAUSS, Primitive classification (R. Needham trad.), London: Cohen and West, 1903/1969.

DURKHEIM, E, "Nota sobre la morfología social", en Las reglas del método sociológico y otros escritos sobre filoso- 
fía de las ciencias sociales (trad. S. González Noriega), Madrid: Alianza, 1897-1898/2000.

DURKHEIM, E., El suicidio. Estudio de Sociología (trad. M. Ruiz-Funes), Madrid: Reus, 1897/1928.

DURKHEIM, E., Las reglas del método sociológico (trad. A. Ferrer), Los Berrocales del Jarama, Madrid: Akal, 1895/1991.

DURKHEIM, E., La división del trabajo social (trad. C. G. Posada), Los Berrocales del Jarama, Madrid: Akal, $1893 / 1995$.

FANG, X., R. ROSENFELD, L. L. DAHLBERG y C. S. FLORENCE, "The nonlinear effect of neighborhood disadvantage on youth violence. Neighborhood effects on youth violence", en Economics and youth violence. Crime, disadvantage, and community (R. ROSENFELD et al. eds.), New York y London: New York University Press, 2013.

FARRINGTON, D. y R. LOEBER, "Early risk factors for convicted homicide offenders and homicide arrestees", en Young homicide offenders and victims. Risk factors, prediction, and prevention from childhood (R. LOEBER y D. FARRINGTON eds.), New York [etc.]: Springer, 2011.

FERRELL, J., K. HAYWARD y J. YOUNG, Cultural Criminology: An invitation, London [etc.]: Sage, 2008.

FRIEDRICHS, D. O., I. SCHOULTZ y A. JORDANOSKA, Edwin H. Sutherland, New York: Routledge, 2018.

GAYLORD, M. S. y J. F. GALLIHER, The Criminology of Edwin H. Sutherland, New Brunswick, NJ y London: Transaction, 1988.

GEERTZ, C. The interpretation of cultures. Selected essays, New York: Basic Books, 1973.

GEIS, G. y C. GOFF, "Introduction”, en E. H. SUTHERLAND, White collar crime. The uncut version, New Haven y London: Yale University Press, 1983.

GIDDENS, A., The constitution of society. Outline of the theory of structuration, Berkeley, Ca.: University of California Press, 1984. 
GIDDENS, A., Durkheim, Glasgow: Fontana/Collins, 1978.

GIDDENS, A., Capitalism and modern social theory. An analysis of the writings of Marx, Durkheim and Max Weber, Cambridge [etc.]: Cambridge University Press, 1971.

GOFFMAN, E., Interaction ritual. Essays on face-to-face behaviour, New York: Anchor Books, 1967.

GONZÁLEZ SÁNCHEZ, I., "La sacralización del individuo utilitarista", en Anomia, cohesión social y moralidad. Cien años de tradición durkheimiana en Criminología (I. GONZÁLEZ SÁNCHEZ y A. SERRANO MAÍLLO eds.), Madrid: Dykinson, 2018.

GOTTFREDSON, M. R. y T. HIRSCHI, A general theory of crime, Stanford, Ca.: Stanford University Press, 1990.

HIRSCHI, T., The craft of Criminology. Selected papers (J. LAUB ed.), New Brunswick, NJ y London: Transaction Publishers, 2002.

HOMANS, G. C., Social behavior. Its elementary forms, 2. ${ }^{\text {a ed., }}$ New York: Harcourt, Brace, Jovanovich, 1974.

HOROWITZ, R., Honor and the American dream. Culture and identity in a Chicano community, New Brunswick, NJ: Rutgers University Press, 1983.

JENCKS, C. y S. E. MAYER, "The social consequences of growing up in a poor neighbourhood", en Inner-city poverty in the United States (L. E. LYNN y M. G. H. MCGEARY eds.), Washington, DC: National Academy Press, 1990.

JENKS, C., Culture, 2. ${ }^{\text {a }}$ ed. London y New York: Routledge, 2005. JENKS, C., Subculture. The fragmentation of the social, London [etc.]: Sage, 2005.

JOLLIFFE, D., J. MURRAY, D. FARRINGTON y C. VANNICK, "Testing the Cambridge Quality Checklists on a review of disrupted families and crime", Criminal Behavior and Mental Health, 22, 5, 2012.

KORNHAUSER, R. R., Social sources of delinquency. An appraisal of analytic models, Chicago y London: University of Chicago Press, 1978. 
LUKES, S., Emile Durkheim. His life and work. A historical and critical study, London: The Penguin Press, 1973.

MAYHEW, B. H., "Structuralism versus individualism: Part 2, Ideological and other obfuscations", Social Forces, 59, 3, 1981 .

MAYHEW, B. H., "Structuralism versus individualism: Part 1, Shadowboxing in the dark", Social Forces, 59, 2, 1980.

MERTON, R. K., Social theory and social structure, edición ampliada, New York: The Free Press, 1968.

MILLER, W., "Lower class culture as a generating milieu of gang delinquency", The Journal of Social Issues, 14, 3. New light on delinquency (W. MCCORD ed.), 1958.

MILLER, W., "The impact of a 'total community' delinquency control project", Social Problems, 10, 1962.

MILLER, W., en W. C. KVARACEUS et al., Delinquent behavior. Culture and the individual, Washington, DC: National Education Association of the United States, 1959.

MURRAY, J., Y. SHENDEROVICH, F. GARDNER, C. MIKTON, J. DERZON, J. LIU y M. EISNER, "Risk factors for antisocial behavior in low- and middle- income countries: A systematic review of longitudinal studies", en Crime and Justice, 47, Chicago, Ill.: The University of Chicago Press, 2018.

MURRAY, J., B. IRVING, D. FARRINGTON, I. COLMAN y C. BLOXSOM, "Very early predictors of conduct problems and crime: results from a national cohort study", Journal of Child Psychology and Psychiatry, 51, 11, 2010.

MURRAY, J., D. FARRINGTON y M. EISNER, "Drawing conclusions about causes from systematic reviews of risk factors. The Cambridge Quality Checklist", Journal of Experimental Criminology, 5, 2009.

OUSEY, G. C. y P. WILCOX, "Subcultural values and violent delinquency. A multilevel analysis in middle schools", Youth Violence and Juvenile Justice, 3, 1, 2005.

PARSONS, T., Social systems and the evolution of action theory, New York: The Free Press, 1977. 
PARSONS, T., The structure of social action, I. Marshall, Pareto, Durkheim, 2. ${ }^{\text {a }}$ ed., New York: The Free Press, 1968.

PARSONS, T., The social system, New York: The Free Press, 1951.

PORPORA, D. V., Reconstructing Sociology. The critical realist approach, Cambridge: Cambridge University Press, 2015.

PORPORA, D. V., "Four concepts of social structure", Journal for the Theory of Social Behavior, 19, 2, 1989.

PRATT, T. y F. CULLEN, "Assessing macro-level predictors and theories of crime: A meta-analysis", en Crime and Justice, 32 (M. TONRY ed.), Chicago, Ill.: The University of Chicago Press, 2005.

PRESDEE, M., Cultural Criminology and the carnival of crime, London y New York: Routledge, 2000.

RADCLIFFE-BROWN, A. R., A natural science of society, New York: Free Press, 1957.

RAWLS, A. W., Epistemology and practice. Durkheim's The elementary forms of religious life, Cambridge [etc.]: Cambridge University Press, 2004.

ROSENFELD, R., C. S. FLORENCE, X. FANG y M. EDBERG, "Introduction", en Economics and youth violence. Crime, disadvantage, and community (R. ROSENFELD et al. eds.), New York y London: New York University Press, 2013.

SAMPSON, R. J., Great American city. Chicago and the enduring neighborhood effect, Chicago [etc.]: University of Chicago Press, 2012.

SANEY, P., Crime and culture in America. A comparative perspective, New York [etc.]: Greenwood, 1986.

SAWYER, R. K., Social emergence. Societies as complex systems, Cambridge [etc.]: Cambridge University Press, 2005.

SELLIN, T., Culture conflict and crime, New York: Social Science Research Council, 1938.

SERRANO MAÍLLO, A., Firmeza frente al delito y comunidad en la modernidad reflexiva. La tesis extendida de los sen- 
timientos de inseguridad como teoría del control social, Madrid: Dykinson, 2016.

SERRANO MAÍLLO, A., El problema de las contingencias en la teoría del autocontrol. Un test de la teoría general del delito, 2. a ed., Madrid: Dykinson, 2013.

SERRANO MAÍlLO, A., Introducción a la Criminología, $6 .{ }^{\mathrm{a}}$ ed., Madrid: Dykinson, 2009.

STEWART, E. A. y R. L. SIMONS, "Race, code of the street, and violent delinquency: A multilevel investigation of neighbourhood street culture and individual norms of violence", Criminology, 48, 2, 2010.

STEWART, E. A., C. J. SCHRECK y R. K. BRUNSON, "Lessons of the street code. Policy implications for reducing violent victimization among disadvantaged citizens", Journal of Contemporary Criminal Justice, 24, 2, 2008.

SULLIVAN, M. L., "Getting paid". Youth crime and work in the inner city, Ithaca y London: Cornell University Press, 1989.

SURRATT, H. L., J. A. INCIARDI, S. P. KURTZ y M. C. KILEY, "Sex work and drug use in a subculture of violence", Crime and Delinquency, 50, 1, 2004.

SUTHERLAND, E. H., The Sutherland papers (A. COHEN et al. eds.), Bloomington, IN: Indiana University Press, 1956.

SUTHERLAND, E. H., Principles of Criminology, $4 .^{\text {a }}$ ed., Chicago [etc.]: J.B. Lippincott, 1949.

SUTHERLAND, E. H., Principles of Criminology, 2. ${ }^{\text {a }}$ ed., Chicago y Philadelphia: J.B. Lippincott, 1934.

SUTHERLAND, E. H., Criminology, Philadelphia y London: J.B. Lippincott, 1924.

SUTHERLAND, E. H. y D. R. CRESSEY, Criminology, 10. ${ }^{\mathrm{a}}$ ed., New York [etc.]: J.B. Lippincott Company, 1978.

SUTHERLAND, E. H. y D. R. CRESSEY, Criminology, 6. ${ }^{\text {a ed., }}$ New York [etc.]: J.B. Lippincott Company, 1960.

SUTHERLAND, E. H., D. R. CRESSEY y D. F. LUCKENBILL, Principles of Criminology, 11. a ed., New York: General Hall, 1992. 
SWIDLER, A., Talk of love. How culture matters, Chicago y London: The University of Chicago Press, 2001.

SWIDLER, A., "Culture in action: symbols and strategies", American Sociological Review, 51, 1986.

TONRY, M., Punishment and politics. Evidence and emulation in the making of English crime control policy, Cullompton, Devon: Willan Publishing, 2004.

TURNER, J.H., "Émile Durkheim's theory of social organization", Social Forces, 68, 4, 1990.

TURNER, J.H., "A behavioral theory of social structure", Journal for the Theory of Social Behavior, 18, 4, 1988.

TURNER, J.H., "Émile Durkheim's theory of integration in differentiated social systems", Pacific Sociological Review, 24, 4, 1981.

WACQUANT, L., "Scrutinizing the street: Poverty, morality, and the pitfalls of urban Ethnography", American Journal of Sociology, 107, 6, 2002.

WACQUANT, L. J. D. y W. J. WILSON, "The cost of racial and class exclusion in the inner city", en The Annals of the American Academy of Political and Social Sciences, 501. The ghetto underclass: Social science perspectives (W. J. WILSON ed.), 1989.

WIKSTRÖM, P.-O. H., D. OBERWITTLER, K. TREIBER y B. HARDIE, Breaking rules. The social and situational dynamics of young people's urban crime, Oxford: Oxford University Press, 2012.

YINGER, J. M., "Contraculture and subculture", American Sociological Review, 25, 5, 1960. 